\title{
Malaria-Associated Acute Kidney Injury in African Children: Prevalence, Pathophysiology, Impact, and Management Challenges
}

\author{
Anthony Batte $\mathbb{I}^{1}$ \\ Zachary Berrens $\mathbb{D D}^{2}$ \\ Kristin Murphy $\mathbb{D}^{3}$ \\ Ivan Mufumba (iD) \\ Maithri L Sarangam (1D ${ }^{5}$ \\ Michael T Hawkes $\mathbb{D D}^{6}$ \\ Andrea L Conroy $\mathbb{D D}^{3}$
}

'Child Health and Development Centre, Makerere University College of Health

Sciences, Kampala, Uganda; ${ }^{2}$ Department of Pediatrics, Pediatric Critical Care Medicine, Indiana University School of Medicine, Indianapolis, IN, USA;

${ }^{3}$ Department of Pediatrics, Ryan White Center for Pediatric Infectious Disease and Global Health, Indiana University School of Medicine, Indianapolis, IN, USA; ${ }^{4}$ CHILD Research Laboratory, Global Health Uganda, Kampala, Uganda; ${ }^{5}$ Department of Global Health, University of Washington, Seattle, WA, USA;

${ }^{6}$ Department of Pediatrics, University of Alberta, Edmonton, Alberta, Canada
Correspondence: Andrea L Conroy Ryan White Center for Pediatric Infectious Disease and Global Health, Indiana University School of Medicine, R4 402C, 1044 West Walnut Street, Indianapolis, IN, 46202, USA

Tel + 317 278-5777

Email conroya@iu.edu

\begin{abstract}
Acute kidney injury (AKI) is emerging as a complication of increasing clinical importance associated with substantial morbidity and mortality in African children with severe malaria. Using the Kidney Disease: Improving Global Outcomes (KDIGO) criteria to define AKI, an estimated $24-59 \%$ of African children with severe malaria have AKI with most AKI community-acquired. AKI is a risk factor for mortality in pediatric severe malaria with a stepwise increase in mortality across AKI stages. AKI is also a risk factor for postdischarge mortality and is associated with increased long-term risk of neurocognitive impairment and behavioral problems in survivors. Following injury, the kidney undergoes a process of recovery and repair. AKI is an established risk factor for chronic kidney disease and hypertension in survivors and is associated with an increased risk of chronic kidney disease in severe malaria survivors. The magnitude of the risk and contribution of malaria-associated AKI to chronic kidney disease in malaria-endemic areas remains undetermined. Pathways associated with AKI pathogenesis in the context of pediatric severe malaria are not well understood, but there is emerging evidence that immune activation, endothelial dysfunction, and hemolysis-mediated oxidative stress all directly contribute to kidney injury. In this review, we outline the KDIGO bundle of care and highlight how this could be applied in the context of severe malaria to improve kidney perfusion, reduce AKI progression, and improve survival. With increased recognition that AKI in severe malaria is associated with substantial post-discharge morbidity and long-term risk of chronic kidney disease, there is a need to increase AKI recognition through enhanced access to creatinine-based and nextgeneration biomarker diagnostics. Long-term studies to assess severe malaria-associated AKI's impact on long-term health in malaria-endemic areas are urgently needed.

Keywords: acute kidney injury, malaria, sub-Saharan Africa, children, mortality, pathophysiology, prevalence, chronic kidney disease, proteinuria, hypertension, creatinine, endothelial activation, hypovolemia, treatment
\end{abstract}

\section{Background}

Despite considerable gains in reducing the global burden of malaria and several countries moving towards elimination, the burden of malaria in sub-Saharan Africa remains disproportionately high. ${ }^{1}$ In 2018, an estimated 213 million malaria cases occurred in sub-Saharan Africa, representing $93 \%$ of global malaria cases. ${ }^{1}$ Children under five years of age represent the most vulnerable group affected by malaria and account for approximately two-thirds of global malaria deaths annually. ${ }^{1}$ Although five Plasmodium spp. cause human malaria infection in sub-Saharan Africa (P. falciparum, 
$P$. malariae, $P$. ovale curtisi, $P$. ovale wallikeri, and $P$. vivax), $P$. falciparum is the most prevalent species in Africa, accounting for an estimated $99.7 \%$ of infections. ${ }^{1}$ Severe malaria is a multi-system disease driven by both host and parasite factors and is defined by the presence of clinical complications, including coma (Blantyre Coma Score <3), deep breathing, multiple convulsions, prostration, shock, abnormal bleeding, and jaundice) as well as the following laboratory measures of disease severity: severe anemia, hypoglycemia, hyperlactatemia, renal impairment, hyperparasitemia. ${ }^{2}$

Recently, there has been an increase in acute kidney injury (AKI) awareness as a clinical complication of importance in pediatric severe malaria. While malaria is well-recognized as a potential cause of AKI or kidney failure in African children and associated with increased mortality, ${ }^{3-10}$ kidney failure was previously considered a rare complication in pediatric populations with severe malaria. ${ }^{2}$ However, several studies over the past decade have transformed our understanding of AKI in malaria in children from a rare complication in severe malaria to a common complication associated with significant morbidity and mortality. The Artesunate versus quinine in the treatment of severe falciparum malaria in African children (AQUAMAT) study identified uremia as a strong predictor of mortality in over 5000 children in sub-Saharan Africa. ${ }^{11}$ While uremia is associated with AKI, it is not specific to kidney injury as blood urea nitrogen is also affected by fluid and nutritional status. More convincing evidence for the importance of acute kidney injury (AKI) emerged in a 2017 meta-analysis evaluating clinical and laboratory predictors of mortality in African children with severe malaria where kidney failure was identified as the strongest predictor of mortality alongside coma. ${ }^{12}$ Although the relationship was strong, it was assessed using various AKI definitions between studies, and data were unavailable in several settings, highlighting the need for additional research to evaluate kidney injury using consensus definitions across different malaria transmission settings and populations.

There are emerging data using consensus definitions to define AKI in severe malaria, reporting AKI in $24-59 \%$ of children hospitalized with severe malaria. ${ }^{13-17}$ When defining AKI, numerous methodologic considerations impact prevalence estimates. This review focuses on AKI in pediatric populations with $P$. falciparum malaria in subSaharan Africa. We discuss methods of assessing kidney function, the limitations of those methods-including evidence on validation of definitions in low-and-middleincome (LMIC) settings - and describe the etiology and pathophysiology of malaria-associated AKI in African children. Finally, we describe management challenges of severe malaria in the context of AKI and highlight priorities for future research.

\section{Consensus Guidelines to Assess Acute Kidney Injury}

Following the recognition that small increases in creatinine in hospitalized patients were associated with increased risk of mortality independent of disease severity and confounders, efforts were made to standardize the evaluation of kidney injury (Table 1). The term AKI was proposed to reflect the disease spectrum associated with kidney failure. The first set of clinical guidelines released were RIFLE (Risk, Injury, Failure, Loss, and End-stage renal disease) released in 2004. ${ }^{18}$ A pediatric RIFLE (pRIFLE) adaptation was published in $2007,{ }^{19}$ followed by the Acute Kidney Injury Network (AKIN) guidelines in $2007^{20}$ that moved away from glomerular filtration rate (GFR) as a measure of kidney function as it cannot be reliably estimated during AKI. AKIN included a threshold to include an abrupt decrease in kidney function (a $0.3 \mathrm{mg}$ / $\mathrm{dL}$ increase in creatinine within 48 hours). In 2012 the Kidney Disease: Improving Global Outcomes (KDIGO) guidelines unified the RIFLE and AKIN guidelines, ${ }^{21}$ with the KDIGO guidelines the preferred criteria to define AKI. ${ }^{21}$

The current KDIGO guidelines provide both a general definition of AKI and criteria to stage kidney injury severity (Table 1). The general definition and AKI stage definitions are based on one of three criteria: a patient's increase in creatinine from baseline, the magnitude of increase in creatinine, or a decrease in urine output. Baseline creatinine should ideally be measured within three months of hospital admission.

\section{Sensitivity of the World Health Organization (WHO) Criteria for Renal Impairment to Detect AKI}

The current WHO severe malaria criteria define renal impairment or AKI as creatinine $>3 \mathrm{mg} / \mathrm{dL}$ for both adults and children. ${ }^{2}$ Normal ranges for creatinine in adults range from $0.5-1.0 \mathrm{mg} / \mathrm{dL}$ in women and $0.7-1.2 \mathrm{mg} / \mathrm{dL}$ in men. Thus, the cut-off of $3 \mathrm{mg} / \mathrm{dL}$ on average would correspond to stage $3 \mathrm{AKI}$, which is associated with a substantial 
Table I Definitions of Acute Kidney Injury

\begin{tabular}{|c|c|c|c|c|c|c|c|c|}
\hline \multicolumn{2}{|c|}{ RIFLE, 2004} & \multicolumn{2}{|c|}{ Pediatric RIFLE, 2007} & \multicolumn{2}{|c|}{ AKIN, 2007} & \multicolumn{2}{|c|}{ KDIGO, 2012} & \multirow[t]{2}{*}{ Urine Output } \\
\hline Criteria & $\begin{array}{l}\text { Creatinine } \\
\text { Definition }\end{array}$ & Criteria & $\begin{array}{l}\text { Creatinine } \\
\text { Definition }\end{array}$ & Criteria & $\begin{array}{l}\text { Creatinine } \\
\text { Definition }\end{array}$ & Criteria & $\begin{array}{l}\text { Creatinine } \\
\text { Definition }\end{array}$ & \\
\hline Risk & $\begin{array}{c}\geq 1.5 x \text { increase in } \\
\mathrm{SCr} \text { from baseline or } \\
\text { decrease in GFR } \\
\geq 25 \%\end{array}$ & Risk & $\begin{array}{l}\text { Decrease in } \\
\text { GFR } \geq 25 \%\end{array}$ & Stage I & $\begin{array}{c}\geq 0.3 \mathrm{mg} / \mathrm{dL} \\
\text { increase in SCr } \\
\text { within } 48 \mathrm{hrs} \text { or } \\
\geq 1.5 \mathrm{x} \text { increase in } \\
\mathrm{SCr} \text { from baseline }\end{array}$ & Stage I & $\begin{array}{l}\geq 0.3 \mathrm{mg} / \mathrm{dL} \text { increase } \\
\text { in } \mathrm{SCr} \text { within } 48 \mathrm{hrs} \\
\text { or } \geq 1.5 \mathrm{x} \text { increase in } \\
\mathrm{SCr} \text { from baseline }\end{array}$ & $\begin{array}{c}<0.5 \mathrm{~mL} / \mathrm{kg} / \mathrm{h} \\
\text { for }>6 \mathrm{hrs}\end{array}$ \\
\hline Injury & $\begin{array}{c}\geq 2 \mathrm{x} \text { increase in } \mathrm{SCr} \\
\text { from baseline or } \\
\text { decrease in GFR } \\
\geq 50 \%\end{array}$ & Injury & $\begin{array}{l}\text { Decrease in } \\
\text { GFR } \geq 50 \%\end{array}$ & Stage 2 & $\begin{array}{c}\geq 2 x \text { increase in } \\
S C r \text { from baseline }\end{array}$ & Stage 2 & $\begin{array}{c}\geq 2 x \text { increase in } \mathrm{SCr} \\
\text { from baseline within } 7 \\
\text { days }\end{array}$ & $\begin{array}{l}<0.5 \mathrm{~mL} / \mathrm{kg} / \mathrm{h} \\
\text { for } \geq 12 \mathrm{hrs}\end{array}$ \\
\hline Failure & $\begin{array}{l}\geq 3 \mathrm{x} \text { increase in } \mathrm{SCr} \\
\text { from baseline or } \\
\text { decrease in GFR } \\
\geq 75 \%, \mathrm{SCr} \geq 4.0 \mathrm{mg} / \\
\mathrm{dL} \text { with an acute } \\
\text { increase of } \\
>0.5 \mathrm{mg} / \mathrm{dL}\end{array}$ & Failure & $\begin{array}{c}\text { Decrease in } \\
\text { GFR } \geq 75 \% \text { or } \\
\text { an } \\
\text { eGFR }<35 \mathrm{~mL} / \\
\text { min per } \\
1.73 \mathrm{~m}^{2}\end{array}$ & Stage 3 & $\begin{array}{l}\geq 3 \mathrm{x} \text { increase in } \\
\mathrm{SCr} \text { from baseline, } \\
\mathrm{SCr} \geq 4.0 \mathrm{mg} / \mathrm{dL} \\
\text { with an acute } \\
\text { increase of } \\
>0.5 \mathrm{mg} / \mathrm{dL} \text { or } \\
\text { initiation of KRT }\end{array}$ & Stage 3 & $\begin{array}{l}\geq 3 \mathrm{x} \text { increase in } \mathrm{SCr} \\
\text { from baseline within } 7 \\
\text { days, } \mathrm{SCr} \geq 4.0 \mathrm{mg} / \mathrm{dL} \\
\text { with an acute increase } \\
\text { of }>0.5 \mathrm{mg} / \mathrm{dL} \text { or } \\
\text { initiation of } \mathrm{KRT}\end{array}$ & $\begin{array}{c}<0.3 \mathrm{~mL} / \mathrm{kg} / \mathrm{h} \\
\text { for } \geq 24 \mathrm{hrs} \text { or } \\
\text { anuria for } \\
\geq 12 \mathrm{hrs}\end{array}$ \\
\hline Loss & Failure for $>4$ weeks & Loss & $\begin{array}{c}\text { Failure for }>4 \\
\text { weeks }\end{array}$ & & & & & \\
\hline ESRD & $\begin{array}{c}\text { Failure for }>3 \\
\text { months }\end{array}$ & ESRD & $\begin{array}{c}\text { Failure for }>3 \\
\text { months }\end{array}$ & & & & & \\
\hline
\end{tabular}

Abbreviations: RIFLE, risk, injury, failure, loss, end-stage renal disease; AKIN, acute kidney injury network; KDIGO, kidney disease: improving global outcomes; SCr, serum creatinine; GFR, glomerular filtration rate; KRT, kidney replacement therapy.

increase in mortality and would fail to recognize a substantial proportion of AKI cases. This is compounded in pediatric patients, where normal creatinine levels are substantially lower and even more so in LMIC pediatric patients where undernutrition - which can cause lower baseline creatinine levels ${ }^{22}$ — is common. In a study of Ugandan children, only $2 / 178$ children (1.1\%) had a peak creatinine $>3 \mathrm{mg} / \mathrm{dL}$, while $46 \%$ met a KDIGO-definition for AKI. ${ }^{13}$ Based on data from our cohorts of Ugandan children with severe malaria, only $4 / 480$ children $(0.8 \%)$ had a creatinine $>3 \mathrm{mg} / \mathrm{dL}$ on admission in a population with an AKI prevalence of $35 \% .{ }^{14}$ In 170 Nigerian children, $7.6 \%$ of children met the WHO criteria for AKI, while $32 \%$ of children met KDIGO-criteria for AKI using creatinine. ${ }^{16}$ The incidence of AKI in African children with severe malaria using KDIGO-consensus guidelines versus non-standard AKI definitions, including the WHO criteria, are presented in Figure 1. Using KDIGOcompatible guidelines with appropriate estimates of baseline creatinine, the incidence of AKI in severe malaria ranges between $24-59 \%{ }^{13-17}$ while using non-standard approaches it ranges from $0-33 \% .^{23-32}$ Thus, the WHO criteria for AKI in severe malaria vastly underestimates AKI in pediatric populations and does not align with current global standards. Revisions should be considered to reflect current evidence and to harmonize definitions and terminology with consensus classifications.

\section{Methodological Considerations When Defining AKI in Children with Severe Malaria}

In the past few years, there have been efforts to validate GFR estimating equations within adult populations in subSaharan Africa, ${ }^{33-35}$ but data from pediatric populations are lacking. ${ }^{36}$ Additional studies to evaluate and standardize approaches to estimate baseline AKI across the pediatric age-spectrum for low-and-middle-income countries are needed to facilitate comparisons across populations and age groups in LMIC and high-income countries (HIC).

Adaptations to the KDIGO guidelines have been proposed in situations where it is challenging to define normal creatinine levels because of rapidly changing levels or in situations where estimates of normal creatinine are 


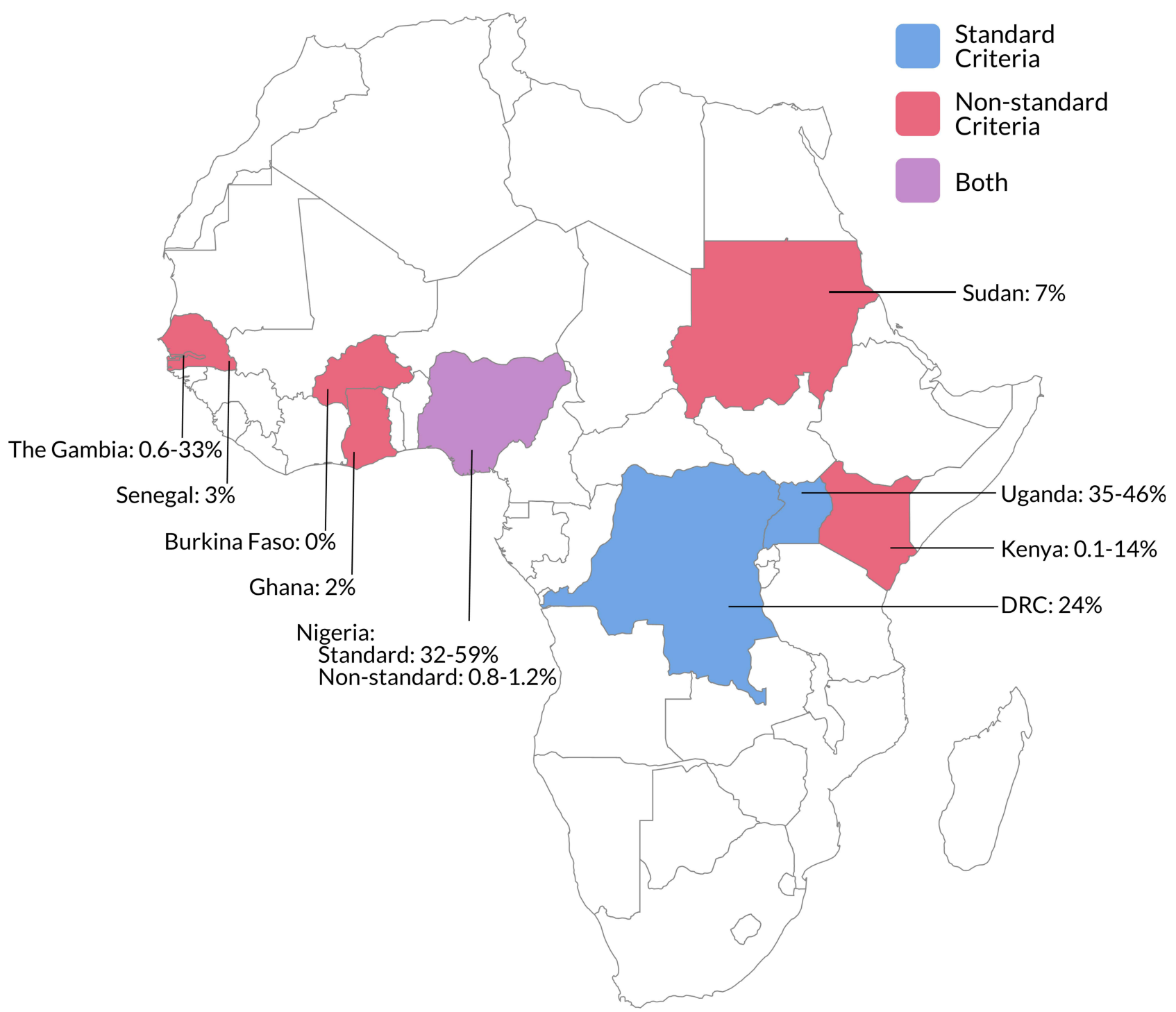

Figure I Incidence of AKI in African children with severe malaria. A literature review was conducted to identify studies that assessed AKI in children with severe malaria, and a total of 15 studies were included. Studies were separated based on whether definitions were consistent with the Kidney Disease: Improving Global Outcomes (KDIGO) criteria to define AKI with an estimate of baseline creatinine (blue) or used non-conventional criteria to define AKI (red) consisting of various creatinine thresholds and/or urine output. One country had studies in both categories (purple). When multiple studies were conducted in the same country, the range of incidence estimates is presented. Studies using standard criteria identified AKI in $24-59 \%$ of children with severe malaria with various approaches to estimate baseline creatinine. ${ }^{13-17}$ Studies using alternative AKI definitions showed a wide range of estimates from 0 to $33 \% .{ }^{23-32}$

lacking. For example, creatinine trajectories in neonates are affected by maternal creatinine levels, gestational age, and innate kidney function. ${ }^{37}$ Thus, within the first week of life, $\mathrm{a} \geq 0.3 \mathrm{mg} / \mathrm{dL}$ rise in creatinine outperforms a percent creatinine change in predicting mortality in neonates (the Assessment of Worldwide Acute Kidney Epidemiology in Neonates, AWAKEN study). ${ }^{37}$ While there have been attempts to evaluate normal baseline creatinine in populations of Ugandan children 6 months to 12 years of age, ${ }^{38}$ additional research is needed to evaluate methods to estimate baseline creatinine across pediatric populations in LMIC, particularly infants $<6$ months of age.

\section{Choice of Baseline Serum Creatinine Measure}

Pre-illness baseline creatinine levels are not available in most - if not all — children. If baseline creatinine is not known in children, it must be estimated. The approach to estimate baseline serum creatinine can lead to substantial differences in AKI incidence and outcome associations. ${ }^{38,39}$ There are two main approaches to estimate baseline creatinine: i) use a known measure from the child; or ii) use population-based estimates (discussed here ${ }^{40}$ ). Patient-specific approaches are best suited in situations where underlying kidney disease is suspected or 
during a period of rapid changes in creatinine. Examples where patient-specific trajectories in creatinine are most appropriate to estimate baseline include: i) neonates where creatinine levels initially reflect maternal levels, are affected by gestational age, and there are rapid changes in postnatal creatinine levels; ii) children with severe malnutrition where creatinine levels are expected to deviate from populationnormal levels; or iii) children with known or suspected chronic kidney disease (CKD).

As most AKI in LMIC is community-acquired and present at hospital admission, using the admission creatinine will lead to vast underestimation of AKI. A recent study in Ghana using the admission creatinine as baseline noted an AKI frequency of $2 \%{ }^{27}$ compared to $32-59 \%$ using population approaches. ${ }^{13-16}$ A study in Ugandan children with serial creatinine measurements over the first four days of hospitalization estimated $79 \%$ of $\mathrm{AKI}$ cases were present on admission. ${ }^{41}$ Another approach to estimate baseline would be to use the discharge or nadir creatinine measure over hospitalization. However, an estimated $7-25 \%$ of children do not recover within $10-50 \%$ of baseline creatinine. ${ }^{9,42}$ Using the discharge creatinine may: i) underestimate $\mathrm{AKI}$, and ii) fail to identify children with persistent kidney injury in need of clinical follow-up.

\section{Importance of Urine Output}

AKI can also be defined using urine output. A large, retrospective study supported the importance of urine output, finding that $67 \%$ of patients diagnosed with AKI by urine output criteria would not have been diagnosed if only plasma creatinine criteria was used. ${ }^{43}$ Furthermore, the adverse outcomes associated with oliguria but not a rise in serum creatinine were comparable to those found in patients who had a rise in serum creatinine alone. ${ }^{43}$ Notably, in a retrospective study of adults, patients with both oliguria and a rise in serum creatinine had worse outcomes than patients who only met one KDIGO criteria. ${ }^{44}$ In practice in many LMICs, urine output is often not assessed in hospitalized children and is difficult to quantify in patients without an indwelling catheter. However, given the importance of urine output in defining AKI, efforts should be made to quantify urine output in hospitalized children, particularly as it does not rely on laboratory testing and is a bedside measure. Whenever feasible, urine output should be quantified at the bedside from toilet trained children or by using pre-weighed, absorbent diapers. When using diapers, efforts should be made to avoid stool contamination by frequently changing diapers or using urine bags with adhesive edges to collect urine. The effect of humidity should also be considered. In high humidity environments, urine output may be overestimated, while in low humidity environments, the impact of evaporative loss can lead to underestimation of urine output. $^{45,46}$ In low-resource settings where limitations in nursing care make assessment of urine output challenging, it may be possible to train caregivers to provide support.

\section{Challenges in AKI Diagnosis and Assessment of AKI Etiology}

There are several challenges when defining AKI in severe malaria and LMIC in general. There is a shortage of nephrologists in sub-Saharan Africa: 9/10 countries with the lowest number of nephrologists are located in subSaharan Africa, and the number of nephrologists per 1 million people ranges from 0.06 to $0.25 .^{47}$ A survey assessing global strategies for improving AKI identification noted that $60 \%$ of African countries had no national strategies for AKI identification. ${ }^{47}$ Challenges in identifying AKI extend beyond limitations in human resource capacity and include shortages in laboratory capacity. Only $12 \%$ of African countries reported that they usually have the services to measure creatinine with eGFR reporting at the primary care level, while 39\% reported they never have the services available. ${ }^{47}$ Even in settings where creatinine measures are available, supply chain issues lead to frequent stock-outs of consumables and a lack of systematic preventive maintenance programs leads to a lack of test availability and delayed results reporting.

\section{Diagnosis of AKI Relies on Accurate Creatinine Measurement}

Throughout the years, there have been several attempts to improve the standardization of laboratory testing of creatinine. The Jaffe method for measuring serum creatinine was discovered in 1886 and is still used today due to its relative simplicity and low-cost. ${ }^{48}$ In this assay, creatinine reacts with picrate in an alkaline environment to produce a color change that can be quantified. ${ }^{49}$ While modern advances have been made to automate this technique, there remain a number of substances, known as pseudochromogens, including bilirubin, which inherently interfere with the reaction. These interfering substances can result in an overestimation of creatinine by as much as $15-25 \%{ }^{50}$ The compensated Jaffe method includes 
a mathematical correction that attempts to correct these interferences, though imprecisions still remain. ${ }^{51}$

Generally considered more sensitive and specific than the Jaffe method, enzymatic assays were introduced in the 1970s and are widely used today in clinical laboratories in HIC to measure creatinine. ${ }^{52}$ Also a colorimetric assay, the enzymatic method is more precise with less interference and relies on consecutive enzymatic reactions. At $\$ 2.00$ per test, the enzymatic assay is more expensive than the Jaffe assay, which costs approximately $\$ 0.30$ per test. ${ }^{53}$ In 2016, the Laboratory Working Group of the National Kidney Disease Education Program outlined standardized isotope dilution mass spectrometry (IDMS) traceability as the preferred method of calibration for creatinine assays to reduce systematic bias. ${ }^{54} \mathrm{~A}$ recent review of studies evaluating kidney function in SubSaharan Africa after 2016 found that $81.7 \%$ of 252 studies did not state whether creatinine measurements were conducted using IDMS traceable assays. Only 6 used the more accurate enzymatic method, while 80 used the Jaffe method. ${ }^{34}$ In countries like Uganda, enzymatic assessment of creatinine is often not available through clinical biochemistry facilities.

At low serum creatinine levels, the mathematical relationship between creatinine and eGFR is exponential, where a small change in a low creatinine level has a substantial impact on the eGFR. However, the same small change in a patient with high creatinine level will have a minimal impact on the calculated eGFR. ${ }^{52}$ This is particularly important in populations with increased filtration and in pediatric populations where creatinine levels are generally low. Imprecisions in the methods used to measure creatinine in these populations will be amplified by the resulting eGFR calculation, which in turn impacts the assessment of kidney disease over recovery.

\section{Defining AKI Etiology}

In addition to creatinine measurements, urine microscopy is a relatively affordable and straightforward diagnostic procedure that laboratories can perform to monitor kidney disease. As microscopy was the foundation of malaria and tuberculosis diagnosis before the advent of rapid diagnostic tests and GeneXpert ${ }^{\circledR}$ systems, there has been considerable investment in expanding microscopic diagnostic capacity across health centers. This capacity could be harnessed with increased training to improve urine microscopy evaluation in health centers. Identifying red blood cells, casts, and kidney tubular epithelial cells in the urinary sediment can provide valuable information in the differential diagnosis of hospitalized patients. ${ }^{55}$ In settings where microscopes or trained technicians are unavailable or in settings where there is unreliable power infrastructure, point-of-care urine dipsticks represent an affordable and accessible alternative. When reporting AKI results, it is recommended that AKI be defined by both AKI stage and cause, rather than stage alone. ${ }^{21}$ For example, reporting AKI stage 3 due to acute tubular necrosis, decreased kidney perfusion/hypovolemia, or post-infectious glomerulonephritis/ rapidly progressive glomerulonephritis. This same etiological approach should also be applied to AKI in children with severe malaria. Etiological investigations facilitate the identification of reversible causes of AKI for which interventions can be initiated early. Additional research is needed to further understand the etiology of AKI in children with severe malaria. In a clinical context, children with AKI should have etiology assessed with adequate clinical evaluation and laboratory investigations.

\section{What is Known About the Etiology and Pathophysiology of Severe Malaria-Associated AKI? \\ Hypovolemia and Hypoperfusion}

Although large-scale studies have not been done to assess the etiology of severe malaria-associated AKI across different settings, most AKI in children with severe malaria is thought to be prerenal and associated with reduced blood flow to the kidney. ${ }^{56}$ Prerenal AKI is associated with a change in kidney function (eg, a rise in creatinine or drop in urine output) without structural damage. Intravascular volume depletion in severe malaria is often the result of inadequate oral fluid intake, increased insensible losses from fever, sometimes complicated by gastrointestinal losses in children with vomiting and/or diarrhea. Shock is an important prognostic factor in children with severe malaria, ${ }^{12}$ occurring in an estimated $57 \%$ of chidren, and hypotension occurring in $13 \%$ of children with severe malaria. ${ }^{57}$ In the context of critical illness, prerenal AKI may be exacerbated by vasoconstriction of afferent arterioles due to medications (eg, non-steroidal anti-inflammatory drugs $^{58}$ ), reduced nitric oxide bioavailability, ${ }^{59}$ or increases in endogenous vasoconstrictors. ${ }^{60}$

\section{Nephrotoxins, Parasite Sequestration, and Hemolysis}

Proximal tubular cells have a high metabolic rate and are susceptible to injury from ischemia or endogenous or 
exogenous toxins. ${ }^{61}$ Endogenous nephrotoxins are a frequent etiological factor of AKI in children in subSaharan Africa. ${ }^{62}$ Ultrastructural examination of kidney tissue of adults with fatal severe malaria reveals parasite sequestration in glomerular and tubulointerstitial vessels and monocyte accumulation in glomerular capillaries. ${ }^{63}$ Although sequestration of parasitized erythrocytes appears to be less frequent in children, malaria pigment occurs in $60 \%$ of distal convoluted tubules, and parasite antigen has been detected in post-mortem kidney tissue. ${ }^{64,65}$ Renal biopsies have also demonstrated malaria pigment and parasite DNA in the kidney tissue of patients with severe malaria-associated AKI. ${ }^{66}$

These findings are supported by studies in adults and children with severe malaria with elevated levels of cellfree hemoglobin and free heme in severe malaria patients with AKI. ${ }^{67-70}$ Hemolysis-mediated kidney injury occurs due to increased oxidative stress, inflammation, endothelial dysfunction, and reduced nitric oxide bioavailability (reviewed $\mathrm{in}^{71}$ ), all of which are implicated in severe malaria pathogenesis.

\section{Endothelial Activation and Microcirculatory Dysfunction}

The kidney is a highly vascularized organ with diverse populations of endothelial cells and diverse functions, including regulating blood flow, glomerular filtration, tubular secretion and reabsorption, hemostasis, and leukocyte trafficking. ${ }^{72}$ Further, the kidney's unique vascularization leads to regional heterogeneity of oxygen supply and differential susceptibility to hypoxia. ${ }^{61}$ Renal biopsies have demonstrated vascular changes, including cortical necrosis, tubular necrosis, and thrombotic microangiopathy in kidney tissue of patients with AKI, supporting a central role for vascular involvement in AKI. ${ }^{66}$ An accumulation of uremic toxins is associated with endothelial damage and microvascular injury in AKI. ${ }^{73}$

Endothelial activation is a central feature of severe malaria pathogenesis and is strongly associated with AKI in severe malaria. ${ }^{67,74,75}$ Endothelial activation contributes to severe malaria pathogenesis by upregulating cellular adhesion molecules like intercellular adhesion molecule-1 (ICAM-1) that mediate cytoadherence of parasitized erythrocytes in the microvasculature, ${ }^{76-78}$ contributing to tissue hypoperfusion, ischemia, metabolic acidosis, and the infiltration of inflammatory leukocytes. ${ }^{76,79-84}$ Endothelial-cell protein $\mathrm{C}$ receptor (EPCR) represents an additional host receptor on the endothelium important for mediating parasite sequestration. ${ }^{77,78,85-89}$ Both EPCR and ICAM-1 are expressed on glomerular and tubular endothelium $^{90,91}$ and could facilitate the sequestration of parasitized erythrocytes in the kidney vasculature. In addition, rosetting, or the adherence of parasitized red blood cells to uninfected red blood cells can lead to vascular congestion and ischemia-reperfusion injury. ${ }^{92,93}$ Sustained hypoperfusion to the kidney can result in structural damage and acute tubular necrosis.

\section{Inflammation and Immune Activation}

Other pathways implicated in severe malaria-associated AKI pathogenesis include immune activation ${ }^{41,69}$ and autoimmune antibodies such as anti-DNA antibodies. ${ }^{94}$ AKI can occur in the absence of hypoperfusion, where inflammatory responses and tubular injury are associated with AKI risk and death. ${ }^{95}$ Endothelial activation in severe malaria contributes to parasite sequestration in the microvasculature, but increased expression of cellular adhesion molecules in the kidney can also contribute to leukocyte recruitment and kidney injury. ${ }^{96,97}$ Briefly, infiltration of immune effector cells in the kidney results in the release of inflammatory cytokines and chemokines that can mediate tissue damage leading to oxidative injury and cell necrosis. These events can be modified by pathogen and host-related proteins that engage pattern-recognition receptors resulting in dysregulated inflammatory responses and tissue injury. The timing and balance of pro- and anti-inflammatory events are critical to minimize excessive cellular damage in the kidney and lead to an appropriate cellular repair process and the return of homeostasis. ${ }^{98}$ In the context of severe malaria, innate immune activation is described with elevated levels of soluble urokinase-type plasminogen activator receptor ${ }^{69}$ and chitinase-3-like- ${ }^{41}$ in AKI. Further, mononuclear cell infiltrates are described in kidney tissue. ${ }^{64}$ To understand the host immune response and tubular injury in severe malariaassociated AKI, prospective studies to assess the kinetics of markers in response to AKI are needed. Cohort studies should collect and store urine, which can yield more specific insights into kidney injury than serum or plasma.

\section{Age-Related Susceptibility to AKI: More Evidence is Needed}

Although previous studies have suggested that increased age is associated with a higher risk of AKI in severe malaria, more recent studies in pediatric populations using KDIGO 
consensus guidelines do not support that association. In Ugandan and Nigerian children with severe malaria, younger children and children $<2$ years of age were shown to have a higher risk of AKI. ${ }^{15,38}$ While it is possible that in lower transmission areas the risk of AKI is higher in older children, the perception of AKI being more common in older children and adults may reflect the serum creatinine threshold used to define AKI in prior studies. An adult with a baseline creatinine of $1.0 \mathrm{mg} / \mathrm{dL}$ requires a three-fold increase in serum creatinine to reach a threshold of $3 \mathrm{mg} / \mathrm{dL}$, while a child with a baseline creatinine of $0.3 \mathrm{mg} / \mathrm{dL}$ requires a 10 -fold increase in creatinine from baseline to meet the threshold for AKI.

\section{Challenges in the Management of AKI in Severe Malaria}

Children with severe malaria have multiple exposures to AKI risk factors that put them at heightened risk of AKI, and therefore clinicians should have a high index of suspicion of AKI in children admitted with severe malaria. Failure to measure kidney function in patients with an increased risk for AKI results in missed opportunities to intervene and mitigate worsening kidney function and lead to disease progression that requires more aggressive therapy and heightened mortality. ${ }^{99,100}$ In addition to effective antimalarial therapy, the provision of appropriate supportive treatment is critical for survival, including correction of hypoglycemia, transfusion for children with severe anemia, oxygen for children with hypoxemia, and fluid administration for children with dehydration or hypovolemia. The KDIGO guidelines provided a framework for managing pediatric patients who are at risk or have developed AKI (Figure 2). ${ }^{21}$ Given the limitations in resources and expertise in LMIC facilities and the heterogeneity between healthcare centers in these settings, providers face significant challenges in achieving these recommendations.

\section{Nephrotoxic Agents and Drug Dosing}

In sub-Saharan Africa, nephrotoxic medications are commonly administered in hospitalized children with the widespread use of aminoglycoside antibiotics and non-steroidal anti-inflammatory medications. Unregulated antibiotic use in the private sector, ${ }^{101}$ widespread self-medication, and use of traditional medicines may lead to nephrotoxic

\section{AKI Stage}

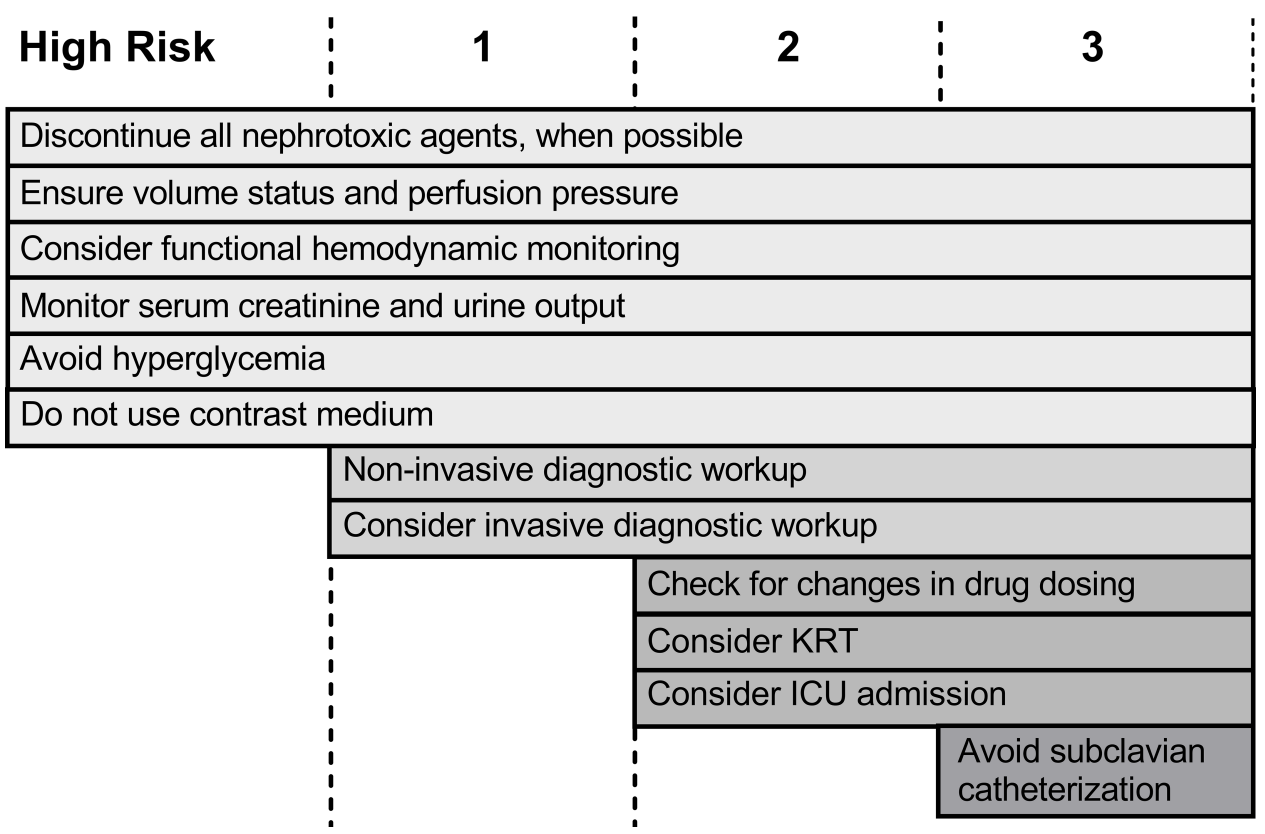

Figure 2 The KDIGO-bundle of treatment measures in patients at risk of AKI and across AKI stages with interventions ranked in importance from top to bottom. The KDIGO-bundle centers on avoiding nephrotoxic substances, optimizing volume status, maintaining normoglycemia, and regular monitoring of serum creatinine and urine output. In malaria endemic areas, there is widespread heterogeneity in access to services across health facilities. Although the KDIGO-bundle of treatment measures will vary based on whether the setting is a specialized hospital or a resource-constrained lower level healthcare facility, components can be adapted across all resource settings. Notes:Reprinted from: Kidney Disease: Improving Global Outcomes (KDIGO) Acute Kidney Injury Work Group. KDIGO Clinical Practice Guideline for Acute Kidney Injury. Kidney International Supplements. 20I2;2(I):I-138. ${ }^{21}$ Copyright (C) 2012 KDIGO, with permission from Elsevier.

Abbreviations: KRT, kidney replacement therapy; ICU, intensive care unit. 
exposure in the community that may exacerbate underlying delays in seeking care. A systematic review of AKI in African children identified nephrotoxins in $16 \%$ of pediatric AKI. ${ }^{62}$ Traditional herbal remedies or toxins can also contribute to AKI. ${ }^{9,62}$ In children with severe malaria, non-essential nephrotoxic medications should be discontinued in children at risk of AKI. Challenges occur when each health center's formulary may be limited in scope and may vary with medication shortages, making it challenging for providers to switch to less nephrotoxic agents when a patient is identified to be at risk or to have developed AKI. Further, clinical pharmacists are not widely available to assist with drug dosing to reduce the nephrotoxic burden. Nevertheless, increased awareness regarding AKI frequency and the importance of avoiding nephrotoxic medications may lead to substantial reductions in worsening or hospital-acquired AKI.

Severe malaria is characterized by high levels of endogenous nephrotoxins resulting from hemolysis leading to the release of cell-free hemoglobin and free heme that are nephrotoxic and induce AKI through increased oxidative stress. ${ }^{68,71}$ The primary contributors to hemolysis in malaria-endemic areas include $P$. falciparum infection, G6PD deficiency, sickle cell anemia, and other hemolytic anemias. Paracetamol represents a potential treatment to prevent AKI through its action as a potent inhibitor of hemoprotein-catalyzed lipid peroxidation (eg, cell-free hemoglobin, myoglobin). ${ }^{102-104} \mathrm{~A}$ study is planned to evaluate the effect of paracetamol on kidney function in 460 children with severe malaria in Kinshasa, Democratic Republic of the Congo (PROTECtS, ClinicalTrials.gov Identifier, NCT04251351).

\section{Fluid Management}

AKI is one of the strongest predictors of mortality in children with severe malaria. ${ }^{12}$ As it is most often community-acquired and associated with prerenal injury, appropriate fluid resuscitation is essential. However, current literature has demonstrated that aggressive fluid administration is associated with poor outcomes in severe malaria. In African children with severe malaria and shock, fluid bolus was associated with increased mortality. ${ }^{105}$ Liberal fluid resuscitation in adults with severe malaria was associated with pulmonary edema and increased mortality. ${ }^{106}$

As tissue hypoxia in severe malaria is associated with parasite sequestration in the microvasculature and not exclusively hypovolemia, liberal administration of fluids may not address the underlying cause of hypoxia and may contribute to fluid overload. Rapid fluid boluses are not recommended in severe malaria resuscitation. A recent prospective study of restricted fluid resuscitation in adults with severe malaria found restrictive fluid management did not worsen kidney function and tissue perfusion in adult patients with severe falciparum malaria and recommended crystalloid administration of $2-3 \mathrm{~mL} / \mathrm{kg}$ per hour during the first 24 hours without bolus therapy unless the patient is hypotensive. ${ }^{107}$ This is lower than the WHO recommendations for fluid resuscitation in pediatric severe malaria ${ }^{108}$ (Box 1).

The majority of pediatric deaths from severe malaria occur during the first 24 hours of hospitalization; $;^{2,25,109-111}$ thus, developing evidence-based guidelines focusing on appropriate early fluid management strategies in children with severe malaria at risk of AKI should be prioritized. Children with AKI are at increased risk of fluid overload. Mechanical ventilation and kidney replacement therapy are often unavailable in malaria-endemic settings in subSaharan Africa; thus, preventing fluid overload is critical. Additional studies evaluating optimal approaches of fluid management in pediatric severe malaria are required.

\section{Hemodynamic Monitoring}

Hemodynamic monitoring can be done non-invasively or invasively. A recent survey of African providers found that almost $94 \%$ had access to non-invasive blood pressure monitoring equipment, but less than a quarter had access to invasive monitoring capabilities. ${ }^{112}$ In addition, although a high percentage of providers had access to noninvasive monitoring equipment, this does not necessarily reflect the reality since the absolute number of automated blood pressure machines in any facility is often far less

Box I WHO Recommendations for Fluid Resuscitation in Pediatric Severe Malaria

I. Immediate correction of hypoglycemia

2. Children unable to retain oral fluids should be managed with $5 \%$ dextrose and/isotonic saline $(0.9 \%)$ maintenance fluids (3$4 \mathrm{~mL} / \mathrm{kg} / \mathrm{hour}$ )

3. Children with severe dehydration receive intravenous Ringer's lactate or $0.9 \%$ isotonic saline. Given as $100 \mathrm{~mL} / \mathrm{kg}$; in children $<12$ months old give $30 \mathrm{~mL} / \mathrm{kg}$ in $\mathrm{Ih}$, then $70 \mathrm{~mL} / \mathrm{kg}$ given over the next $5 \mathrm{~h}$. While in children $\geq 12$ months old, give $30 \mathrm{~mL} / \mathrm{kg}$ over 30 minutes, then $70 \mathrm{~mL} / \mathrm{kg}$ over the $2 \mathrm{~h}$. Repeat the first dose of $30 \mathrm{~mL} / \mathrm{kg}$ if the radial pulse is still very weak or not detectable

4. A careful record of fluid input and output. If not possible, measure weight daily to assess fluid balance 
than the number of patients who meet an indication for serial monitoring. There must be adequate nursing available to see, document, and communicate vital signs to clinicians with any serial vital sign monitoring. The nurse to patient ratio at some facilities may not make this feasible even when the equipment is present.

\section{Creatinine and Urine Output Monitoring}

For serum creatinine to have utility in AKI management, the test must be accessible, and results must be available in a clinically relevant timeframe. Inconsistencies between facilities' capacity for testing, collection, and turn-around time to results, coupled with underdeveloped hospital record systems, make serial monitoring of serum creatinine difficult.

As was previously mentioned, monitoring urine output is also challenging. It is rare to have pediatric patients with indwelling urinary catheters to assess urine output accurately. In younger patients, diapers are not routinely weighed, and older patients are not routinely provided urinary catch receptacles, allowing for easy measurement of urine with each void. In instances where it is not possible to assess fluid input and output, daily weights can be taken to monitor fluid balance, but this does not help diagnose AKI.

\section{Avoiding Hyperglycemia}

When considering the clinical management of severe malaria, it is important to consider glucose monitoring. Children with severe malaria are susceptible to hypoglycemia with malnutrition, younger age, an inability to eat or drink, and altered consciousness as risk factors. ${ }^{2}$ In settings where glucose monitoring is unavailable and children present with coma, it is clinically important to rule out hypoglycemia as a cause. As such, glucose bolus is a critical component in managing severe malaria and is often administered without glucose monitoring. Glucose monitoring and maintenance of normoglycemia are important as stress hyperglycemia is common among critically ill children and associated with increased mortality. In children with severe malaria in Mozambique, continuous glucose monitoring identified hypoglycemia in $15.4 \%$ of children and hyperglycemia (glucose $\geq 11.0 \mathrm{mmol} / \mathrm{L}$ ) in $15.9 \%$ of children, although rare on admission. ${ }^{113}$ In Ugandan children with severe malaria, 35\% had a glucose measurement $>6.8 \mathrm{mmol} / \mathrm{L} .{ }^{114}$ In ICU populations in high-resource settings, there is some evidence that maintaining normoglycemia may reduce $\mathrm{AKI}{ }^{21}$ In the context of severe malaria, where routine glucose monitoring is not always available, the risks of hypoglycemia likely outweigh the potential benefits of maintaining normoglycemia. In settings where continuous glucose monitoring is possible, attempts to avoid hyperglycemia are warranted. Additional studies are needed to elucidate whether hyperglycemia is a risk factor for AKI in the context of severe malaria or a reflection of multi-organ dysfunction and metabolic dysfunction.

\section{Kidney Replacement Therapy}

To substantially reduce mortality associated with severe malaria in children, increased access to kidney replacement therapy is critical. Baelani et al ${ }^{112}$ found that only $36 \%$ of African providers always had access to peritoneal dialysis, with slightly more (43.2\%) always having access to hemodialysis/hemofiltration. There have been efforts by the Saving Young Lives program of the International Society of Nephrology to expand access to pediatric peritoneal dialysis in Africa. Among 32 dialyzed children with AKI in the Democratic Republic of Congo, 75\% recovered normal kidney function within 3 months of discharge, ${ }^{115}$ and although mortality was still high at $18.7 \%$, it was substantially lower than the estimated $73 \%$ in children in whom dialysis is indicated but not available. ${ }^{62}$ In Cameroon, efforts to increase peritoneal dialysis through locally produced solutions compared to commercial solutions resulted in comparable mortality and peritonitis rates, ${ }^{116}$ emphasizing how initial investments in training and capacity can be sustained through locally-driven solutions. To reduce mortality associated with malaria - and improve long-term outcomesthere must be efforts to provide dialysis to sustain life and give the kidney enough time to recover.

\section{Impact of AKI on Short-Term and Long-Term Outcomes Survival, Length of Hospital Stay, and Risk of Readmission or Death}

Many retrospective studies show that AKI is associated with increased mortality, length of hospitalization, need for kidney replacement therapy, and mechanical ventilation in highincome countries. ${ }^{117-119}$ These data are supported by a large, prospective, international study, ${ }^{43}$ which demonstrated a stepwise increase in the risk of mortality across KDIGOdefined AKI stages. AKI is a well-established risk factor for mortality in children with severe malaria ${ }^{12-15,120}$ and is associated with prolonged duration of hospitalization. ${ }^{13}$ 
$\mathrm{AKI}$ is associated with increased post-discharge mortality in severe malaria ${ }^{14}$ and increased readmission or mortality in both pediatric and adult AKI survivors in high-income settings. ${ }^{121-126}$ Children with severe malaria are at increased risk of readmission following discharge, ${ }^{127-130}$ but the relationship between AKI and readmission in children with severe malaria has not been investigated. A recent study has implicated hemoglobinuria or blackwater fever with post-discharge morbidity and mortality. ${ }^{131}$ Blackwater fever is well described in children with severe malaria-associated AKI and likely related to hemolysis and the release of endogenous nephrotoxins. ${ }^{7,14,17,132,133}$ Additional research is needed to understand the relationship between blackwater fever and AKI.

\section{Disability on Discharge and Long-Term Brain Injury}

There is increasing evidence that AKI is associated with neurologic deficits in severe malaria survivors ${ }^{13,14}$ and is a risk factor for long-term neurocognitive deficits and behavioral problems in survivors. ${ }^{14,134}$ In Ugandan children, the relationship between AKI and brain injury remained significant following adjustment for disease severity and was associated with endothelial activation, $^{74}$ blood-brain-barrier dysfunction, ${ }^{14}$ and increased tau - a marker of axonal injury - in the cerebrospinal fluid. ${ }^{135}$ Thus, the epidemiological associations are consistent with laboratory findings supporting a biological link between brain injury and AKI. There are also emerging data from pediatric sepsis cohorts identifying AKI as a risk factor for disability in survivors. ${ }^{136,137}$

\section{Kidney Recovery Following Injury}

There is a growing body of evidence that kidney dysfunction may persist following an AKI episode, which may culminate into chronic kidney disease. Kidney disease is classified as acute (acute kidney disease, AKD) if $\leq 3$ months and chronic (chronic kidney disease, CKD) when disease persists for more than three months ${ }^{21,138,139}$ (Figure 3). AKI represents a subset of AKD in which there is an abrupt decrease in kidney function within one week. AKI and AKD may appear to resolve in the shortterm but can lead to an increased long-term risk of CKD. ${ }^{140} \mathrm{CKD}$ also represents a risk factor for AKI, and $\mathrm{AKI}$, in turn, can accelerate CKD progression leading to worsening glomerular filtration rate or albuminuria. ${ }^{21}$

AKI can lead to nephron loss and reduced kidney functional reserve which may not be evident based on creatinine levels. The ability to detect a decline in kidney function is affected by age. Even when an AKI episode

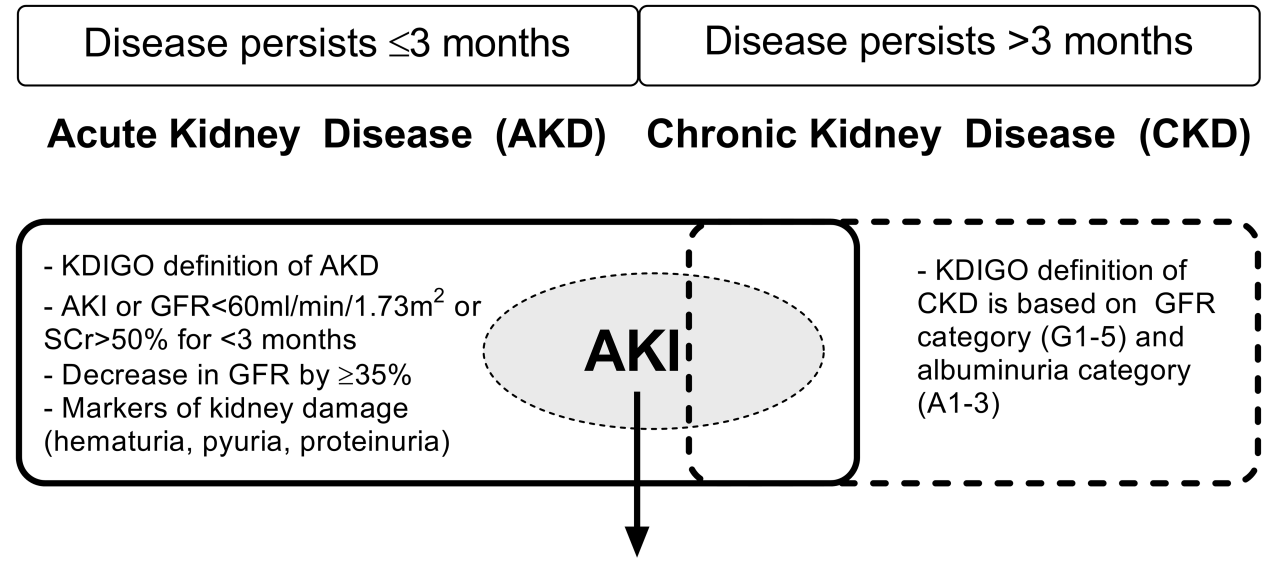

\section{AKI is a subset of AKD and can occur in the context of CKD. AKI is a sudden decrease in GFR manifested by an increase in creatinine or decrease in urine output within one week.}

\footnotetext{
Figure 3 An overview of AKI, AKD, and CKD. Overlapping boxes depict the interrelationships among AKI, AKD, and CKD. AKI is a subset of AKD, and both AKI and AKD can be superimposed on CKD. Acute kidney diseases (AKD) are $\leq 3$ months in duration, and CKD is kidney disease present $>3$ months. Note: Definitions and concepts data from Kidney Disease: Improving Global Outcomes (KDIGO) Acute Kidney Injury Work Group. ${ }^{21}$
} 
leads to significant kidney damage, the functional impairment manifested by an increase in serum creatinine may not manifest until a child enters adolescence and experiences a growth spurt with an increase in metabolic load. ${ }^{141}$

The kidney is susceptible to injury and has a limited capacity for repair that involves cellular differentiation and proliferation. Proximal tubular cells have a high metabolic rate and are susceptible to injury from ischemia or endogenous or exogenous toxins. ${ }^{61}$ Following the loss of tubular cells from injury, epithelial cells can re-differentiate and replace lost or damaged cells as part of the natural repair process. ${ }^{142}$ However, perturbations in the repair process can lead to fibrosis, or the development of CKD, placing survivors at risk for reduced lifespan and comorbidities, including cardiovascular disease, or kidney failure. ${ }^{142}$

As the burden of non-communicable diseases increases in LMIC and there is an increase in CKD, it is important to identify potentially modifiable risk factors. ${ }^{139}$ An underappreciated risk factor for CKD may be severe or repeated AKI or AKD episodes that accumulate over a lifetime leading to nephron loss and CKD. The relationship between AKI-AKD -CKD has been evaluated in several adult and pediatric populations. A review of kidney sequelae following AKI in pediatric populations was recently carried out by Sigurjonsdottir et al. ${ }^{143}$ Following AKI defined using consensus criteria, the prevalence of proteinuria ranges from 42 $69 \%$, hypertension from $3-38 \%$, and $13-15 \%$ of children have a GFR $<90 \mathrm{~mL} / \mathrm{min} / 1.73 \mathrm{~m}^{2} .{ }^{144-149}$ The relationship between AKI and CKD has not been systematically investigated in children in LMIC.

Previously, we reported a 2.81 fold $(95 \%$ CI $1.02,7.73)$ increased odds of CKD (eGFR $<90 \mathrm{~mL} / \mathrm{min}$ per $\left.1.73 \mathrm{~m}^{2}\right)$ at one-year follow-up in Ugandan children following AKI in severe malaria. ${ }^{14}$ Studies are ongoing to evaluate the prevalence of CKD between 4-20 years following severe malaria and to assess the relationship between AKI and CKD.

\section{Moving Forward: How Do We Diagnose AKI in Settings with Limited Testing Infrastructure?}

Limitations in laboratory infrastructure in sub-Saharan Africa impact the ability to assess AKI in clinical settings. Access to specialized diagnostic tests often relies on out-of-pocket payment by patients highlighting the need for affordable diagnostics that are amenable to
Box 2 What Tests are Needed When AKI is Suspected?

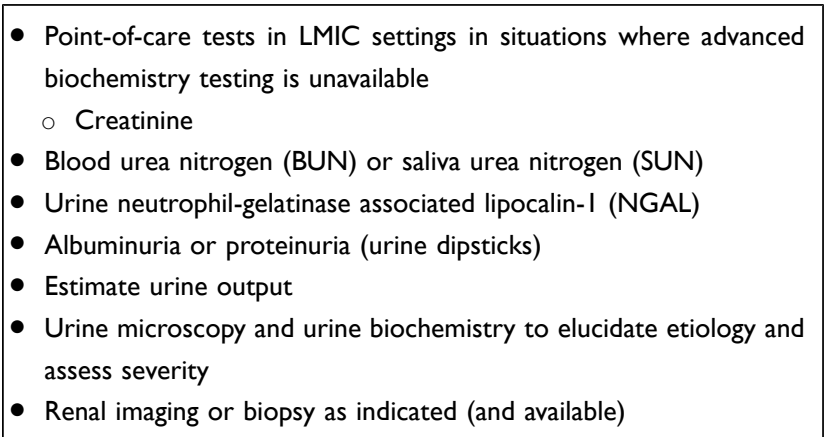

widespread use in public facilities. Affordable and accessible diagnostics are critical to improving diagnosis and clinical management of AKI and should reflect functional or structural measures of kidney disease (Box 2).

Several point-of-care creatinine tests can be used in healthcare settings without a centralized laboratory and creatinine test capacity. Diagnostics for identification of AKI in LMIC have been recently reviewed, including seven point-of-care platforms for creatinine testing with approximate costs ranging from $\$ 4000$ to 20,000 USD for the devices and the cost per test from $\$ 4-20 .{ }^{150}$ In addition to relatively high prices for tests, logistical and practical challenges remain with strips or cartridges requiring refrigeration and having a relatively short shelf-life. ${ }^{150}$ Alternative biomarkers of AKI that may have potential for use in malaria-endemic areas for increased AKI recognition are discussed below.

Blood urea nitrogen (BUN) accumulates in the blood when kidney function decreases. In Ugandan children with severe malaria, BUN is strongly correlated with AKI and outperforms serum creatinine in predicting mortality. ${ }^{13}$ The prognostic utility of BUN has been demonstrated in over 5000 African children with severe malaria across 11 sites in 9 African countries. ${ }^{11}$ BUN is water-soluble and can be monitored non-invasively in saliva (saliva urea nitrogen, SUN) at \$1-2 using a semiquantitative lateral flow dipstick. Studies assessing the discriminative ability of dipstick SUN to detect elevated BUN have reported sensitivities ranging from $77-85 \%$ and specificities of $85-88 \% .{ }^{150}$ SUN has been tested in several adult populations, including populations in lowresource settings, where SUN had good performance of identifying AKI with areas under the ROC curve $>0.80 .{ }^{151-155}$ There is now evidence that SUN can 
identify children with AKI in sub-Saharan Africa ${ }^{156}$ with additional studies ongoing.

Neutrophil gelatinase-associated lipocalin (NGAL) is a $25 \mathrm{kDa}$ glycoprotein expressed and secreted by kidney tubular cells and is considered an early biomarker of kidney injury. ${ }^{157}$ Recently, a lateral-flow test strip was developed by BioPorto that can facilitate rapid quantitation of urinary NGAL (uNGAL) in resource-limited settings. ${ }^{158}$ The uNGAL lateral-flow test is easy to perform, and results can be quantified using a digital strip reader. Several other putative AKI biomarkers have been identified related to glomerular function, ${ }^{159,160}$ tubulointerstitial injury, ${ }^{161,162}$ cell cycle arrest inhibitors, ${ }^{163}$ endothelial activation, ${ }^{164,165}$ and inflammation. ${ }^{165,166}$ At present, there are limited data on performance of AKI biomarkers in populations of
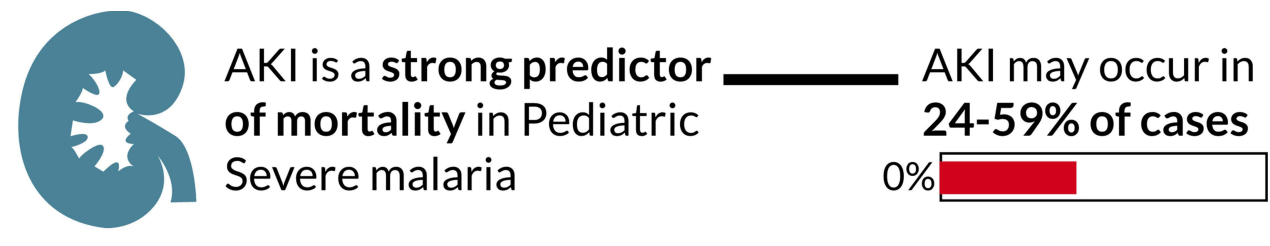

\section{More Research is Needed}
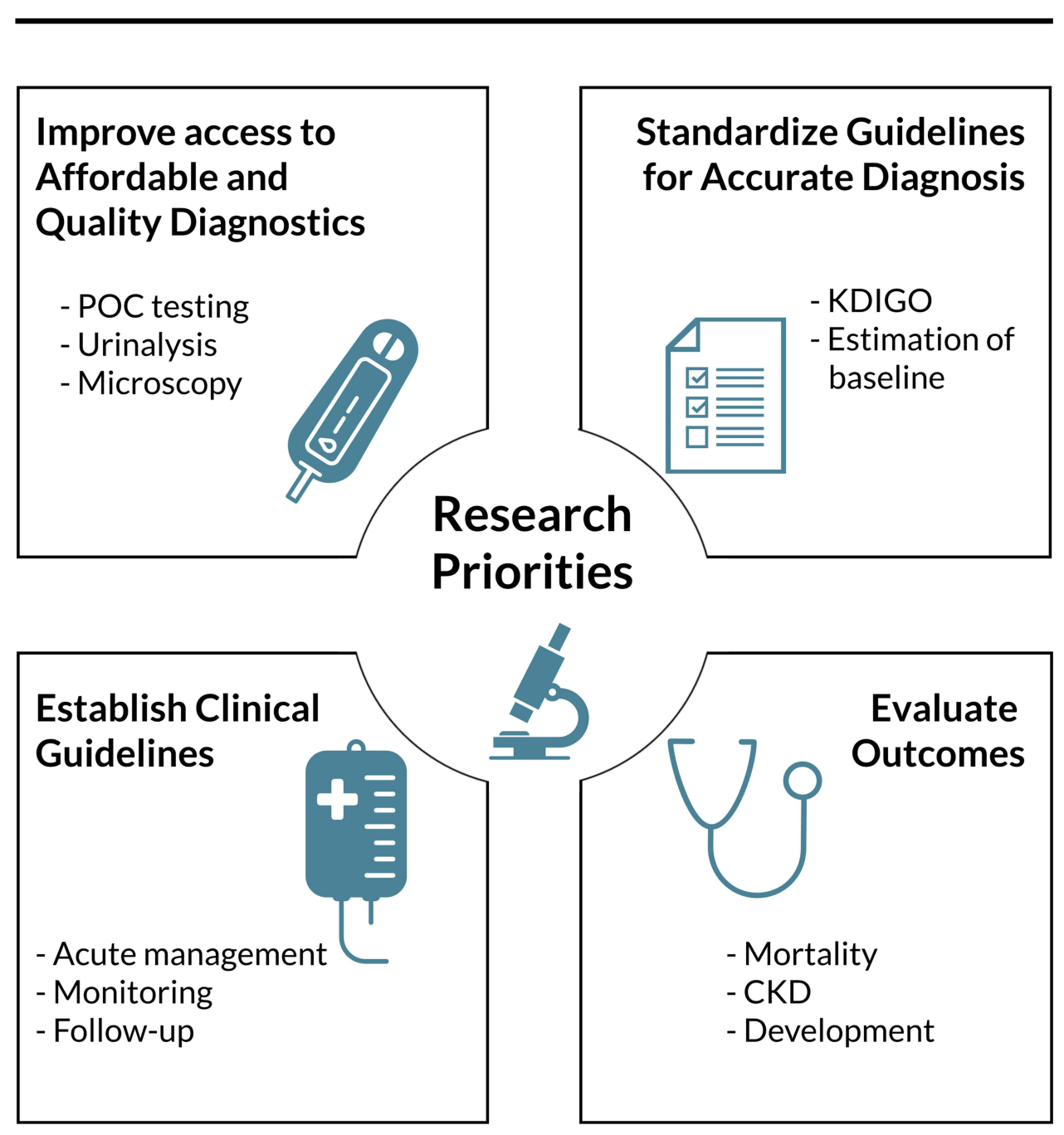

Figure 4 Research priorities for improved detection, diagnosis, and clinical management of AKI in children with severe malaria. In the context of pediatric severe malaria, we highlight four research priorities: I) increased access to affordable and quality diagnostics, 2) use of standardized guidelines for accurate diagnosis that include unified approaches of estimating baseline serum creatinine in defining kidney disease and harmonizing nomenclature across studies, 3) establishing evidence-based clinical guidelines for acute management of severe malaria in the context of a high burden of $\mathrm{AKI}$, and developing guidelines on appropriate monitoring and follow-up of recovery following kidney injury, 4) to evaluate outcomes associated with AKI in severe malaria focusing on mortality, long-term chronic kidney disease (CKD) and child neurodevelopment. 
children with severe malaria. There is a critical need for investment to evaluate the utility of existing AKI biomarkers and evaluate the diagnostic performance of novel biomarkers in the early diagnosis of severe malaria-associated AKI.

Although there remain barriers to the routine assessment of AKI in populations at high risk of disease, a high index of suspicion and appropriate implementation of available tools can improve the identification and clinical management of AKI. A summary of recommended tests is provided in Box 2, and the KDIGO-clinical management guidelines in Figure 2 are outlined with the capacity to improve the care of children with severe malaria.

\section{Future Directions: Priorities for Research}

In summary, AKI is a frequent clinical complication in children with severe malaria and is associated with considerable morbidity and mortality. We outline a series of research priorities in Figure 4 to improve the detection, diagnosis, and clinical management of AKI in children with severe malaria. The long-term consequences of AKI in children with severe malaria remain understudied, but AKI likely contributes to long-term CKD in malariaendemic areas. To understand the long-term impact of AKI across the lifespan, additional research is needed to improve access to affordable and quality diagnostics to facilitate the early identification of AKI and AKD. To evaluate outcomes across settings, standardized guidelines must be applied using comparable approaches to estimate baseline serum creatinine in populations. Clear and context-specific clinical guidelines are urgently needed that can be adapted and applied in resource-constrained rural clinics and well-resourced intensive care units at public and private health facilities. Finally, long-term cohorts are needed to evaluate the relationship between AKI, AKD, and both short-term and long-term health-related quality of life following severe malaria in children.

\section{Disclosure}

The authors reported no conflicts of interest for this work.

\section{References}

1. WHO. World Malaria Report 2019. Geneva: World Health Organization; 2019.
2. World Health Organization. Severe malaria. Trop Med Int Health. 2014;19(Suppl 1):7-131.

3. Ademola AD, Asinobi AO, Ekpe-Adewuyi E, et al. Acute kidney injury among paediatric emergency room admissions in a tertiary hospital in South West Nigeria: a cohort study. Clin Kidney J. 2019;12(4):521-526. doi:10.1093/ckj/sfy120

4. Esezobor CI, Ladapo TA, Lesi FE. Clinical profile and hospital outcome of children with severe acute kidney injury in a developing country. J Trop Pediatr. 2015;61(1):54-60. doi:10.1093/tropej/fmu066

5. Esezobor CI, Ladapo TA, Osinaike B, Lesi FE. Paediatric acute kidney injury in a tertiary hospital in Nigeria: prevalence, causes and mortality rate. PLoS One. 2012;7(12):e51229. doi:10.1371/ journal.pone.0051229

6. Imani PD, Odiit A, Hingorani SR, Weiss NS, Eddy AA. Acute kidney injury and its association with in-hospital mortality among children with acute infections. Pediatr Nephrol. 2013;28 (11):2199-2206. doi:10.1007/s00467-013-2544-2

7. Aloni MN, Nsibu CN, Meeko-Mimaniye M, Ekulu PM, Bodi JM. Acute renal failure in congolese children: a tertiary institution experience. Acta Paediatr. 2012;101(11):e514-e518. doi:10.1111/ j.1651-2227.2012.02827.x

8. Olowu WA, Adelusola KA. Pediatric acute renal failure in southwestern Nigeria. Kidney Int. 2004;66(4):1541-1548. doi:10.1111/ j.1523-1755.2004.00918.x

9. Evans RD, Hemmila U, Craik A, et al. Incidence, aetiology and outcome of community-acquired acute kidney injury in medical admissions in Malawi. BMC Nephrol. 2017;18(1):21. doi:10.1186/s12882-017-0446-4

10. Anigilaje EA, Adebayo AI, Ocheni SA. Acute kidney injury in children: a study of etiology, clinical profile, and short-term outcomes at the University of Abuja Teaching Hospital, Gwagwalada, Abuja, Nigeria. Saudi J Kidney Dis Transpl. 2019;30(2):421-439. doi:10.4103/1319-2442.256849

11. von Seidlein L, Olaosebikan R, Hendriksen IC, et al. Predicting the clinical outcome of severe falciparum malaria in african children: findings from a large randomized trial. Clin Infect Dis. 2012;54(8):1080-1090. doi:10.1093/cid/cis034

12. Sypniewska P, Duda JF, Locatelli I, Althaus CR, Althaus F, Genton B. Clinical and laboratory predictors of death in African children with features of severe malaria: a systematic review and meta-analysis. BMC Med. 2017;15(1):147. doi:10.1186/s12916017-0906-5

13. Conroy AL, Hawkes M, Elphinstone RE, et al. Acute kidney injury is common in pediatric severe malaria and is associated with increased mortality. Open Forum Infect Dis. 2016;3(2): ofw046. doi:10.1093/ofid/ofw046

14. Conroy AL, Opoka RO, Bangirana P, et al. Acute kidney injury is associated with impaired cognition and chronic kidney disease in a prospective cohort of children with severe malaria. BMC Med. 2019;17(1):98. doi:10.1186/s12916-019-1332-7

15. Oshomah-Bello EO, Esezobor CI, Solarin AU, Njokanma FO. Acute kidney injury in children with severe malaria is common and associated with adverse hospital outcomes. $J$ Trop Pediatr. 2020;66(2):218-225. doi:10.1093/tropej/fmz057

16. Afolayan FM, Adedoyin OT, Abdulkadir MB, et al. Acute kidney injuries in children with severe malaria: a comparative study of diagnostic criteria based on serum cystatin $\mathrm{C}$ and creatinine levels. Sultan Qaboos Univ Med J. 2020;20(4):e312-e317. doi:10.18295/squmj.2020.20.04.006

17. Kunuanunua TS, Nsibu CN, Gini-Ehungu JL, et al. Acute renal failure and severe malaria in Congolese children living in Kinshasa, Democratic Republic of Congo. Nephrol Ther. 2013;9 (3):160-165. doi:10.1016/j.nephro.2013.01.001 
18. Bellomo R, Ronco C, Kellum JA, Mehta RL, Palevsky P. Acute dialysis quality initiative w. Acute renal failure - definition, outcome measures, animal models, fluid therapy and information technology needs: the second international consensus conference of the Acute Dialysis Quality Initiative (ADQI) Group. Crit Care. 2004;8(4):R204-R212. doi:10.1186/cc2872

19. Akcan-Arikan A, Zappitelli M, Loftis LL, Washburn KK, Jefferson LS, Goldstein SL. Modified RIFLE criteria in critically ill children with acute kidney injury. Kidney Int. 2007;71 (10):1028-1035. doi:10.1038/sj.ki.5002231

20. Mehta RL, Kellum JA, Shah SV, et al. Acute kidney injury network: report of an initiative to improve outcomes in acute kidney injury. Crit Care. 2007;11(2):R31. doi:10.1186/cc5713

21. Kidney Disease: Improving Global Outcomes (KDIGO) Acute Kidney Injury Work Group. KDIGO clinical practice guideline for acute kidney injury. Kidney Int Suppl. 2012;2(1):1-138.

22. Klahr S, Alleyne GA. Effects of chronic protein-calorie malnutrition on the kidney. Kidney Int. 1973;3(3):129-141. doi:10.1038/ ki.1973.21

23. Ajetunmobi WA, Orimadegun AE, Brown BJ, et al. Haemoglobinuria among children with severe malaria attending tertiary care in Ibadan, Nigeria. Malar J. 2012;11(1):336 doi:10.1186/1475-2875-11-336

24. Orimadegun A, Ogunbosi B, Orimadegun B. Hypoxemia predicts death from severe falciparum malaria among children under 5 years of age in Nigeria: the need for pulse oximetry in case management. Afr Health Sci. 2014;14(2):397-407. doi:10.4314/ahs.v14i2.16

25. Marsh K, Forster D, Waruiru C, et al. Indicators of life-threatening malaria in African children. $N$ Engl J Med. 1995;332(21):1399-1404. doi:10.1056/NEJM199505253322102

26. Sowunmi A. Clinical study of cerebral malaria in African children. Afr J Med Med Sci. 1997;26(1-2):9-11.

27. Ephraim RK, Adoba P, Sakyi SA, et al. Acute kidney injury in pediatric patients with malaria: a prospective cross-sectional study in the shai-osudoku district of Ghana. Saudi J Kidney Dis Transpl. 2020;31(1):235-244. doi:10.4103/1319-2442.279946

28. Weber MW, Zimmermann U, van Hensbroek MB, et al. Renal involvement in Gambian children with cerebral or mild malaria. Trop Med Int Health. 1999;4(5):390-394. doi:10.1046/j.13653156.1999.00409.x

29. Jallow M, Casals-Pascual C, Ackerman H, et al. Clinical features of severe malaria associated with death: a 13-year observational study in the Gambia. PLoS One. 2012;7(9):e45645. doi:10.1371/ journal.pone. 0045645

30. Sanou I, Paré J, Traoré S, et al. Clinical signs of severe malaria in a pediatric hospital in Ouagadougou. Sante. 1997;7(1):13-17.

31. Gerardin P, Rogier C, Ka AS, Jouvencel P, Brousse V, Imbert P. Prognostic value of thrombocytopenia in African children with falciparum malaria. Am J Trop Med Hyg. 2002;66(6):686-691. doi:10.4269/ajtmh.2002.66.686

32. Hashim HA, Ali EMA. Pattern of malaria in hospitalized children in Khartoum state. Sudan J Paediatr. 2017;17(2):35-41. doi:10.24911/SJP.2017.2.4

33. George JA, Brandenburg JT, Fabian J, et al. Kidney damage and associated risk factors in rural and urban sub-Saharan Africa (AWI-Gen): a cross-sectional population study. Lancet Glob Health. 2019;7(12):e1632-e1643. doi:10.1016/S2214-109X(19) 30443-7

34. Fabian J, George JA, Etheredge HR, et al. Methods and reporting of kidney function: a systematic review of studies from sub-Saharan Africa. Clin Kidney J. 2019;12(6):778-787. doi:10.1093/ckj/sfz089

35. Kalyesubula R, Fabian J, Nakanga W, et al. How to estimate glomerular filtration rate in sub-Saharan Africa: design and methods of the African Research into Kidney Diseases (ARK) study. BMC Nephrol. 2020;21(1):20. doi:10.1186/s12882-020-1688-0
36. Kayange NM, Smart LR, Tallman JE, et al. Kidney disease among children in sub-Saharan Africa: systematic review. Pediatr Res. 2015;77(2):272-281. doi:10.1038/pr.2014.189

37. Askenazi D, Abitbol C, Boohaker L, et al. Optimizing the AKI definition during first postnatal week using Assessment of Worldwide Acute Kidney Injury Epidemiology in Neonates (AWAKEN) cohort. Pediatr Res. 2019;85(3):329-338. doi:10.1038/s41390-018-0249-8

38. Batte A, Starr MC, Schwaderer AL, et al. Methods to estimate baseline creatinine and define acute kidney injury in lean Ugandan children with severe malaria: a prospective cohort study. BMC Nephrol. 2020;21(1):417. doi:10.1186/s12882-02002076-1

39. Zappitelli M, Parikh CR, Akcan-Arikan A, Washburn KK, Moffett BS, Goldstein SL. Ascertainment and epidemiology of acute kidney injury varies with definition interpretation. Clin $J$ Am Soc Nephrol. 2008;3(4):948-954. doi:10.2215/ CJN.05431207

40. De Rosa S, Samoni S, Ronco C. Creatinine-based definitions: from baseline creatinine to serum creatinine adjustment in intensive care. Crit Care. 2016;20:69. doi:10.1186/s13054-016-1218-4

41. Conroy AL, Hawkes MT, Elphinstone R, et al. Chitinase-3-like 1 is a biomarker of acute kidney injury and mortality in paediatric severe malaria. Malar J. 2018;17(1):82. doi:10.1186/s12936-0182225-5

42. Hessey E, Ali R, Dorais M, et al. Renal function follow-up and renal recovery after acute kidney injury in critically ill children. Pediatr Crit Care Med. 2017;18(8):733-740. doi:10.1097/ PCC.0000000000001166

43. Kaddourah A, Basu RK, Bagshaw SM, Goldstein SL, Investigators A. Epidemiology of acute kidney injury in critically ill children and young adults. $N$ Engl J Med. 2017;376(1):11-20. doi:10.1056/NEJMoa1611391

44. Kellum JA, Sileanu FE, Murugan R, Lucko N, Shaw AD, Clermont G. Classifying AKI by urine output versus serum creatinine level. $J$ Am Soc Nephrol. 2015;26(9):2231-2238. doi:10.1681/ASN.2014070724

45. Cooke RJ, Werkman S, Watson D. Urine output measurement in premature infants. Pediatrics. 1989;83(1):116-118.

46. Oddie S, Adappa R, Wyllie J. Measurement of urine output by weighing nappies. Arch Dis Child Fetal Neonatal. 2004;89(2): F180-F181. doi:10.1136/adc.2002.018853

47. Bello AK, Levin A, Tonelli M, et al. Assessment of global kidney health care status. JAMA. 2017;317(18):1864-1881. doi:10.1001/ jama.2017.4046

48. Delanghe JR, Speeckaert MM. Creatinine determination according to jaffe-what does it stand for? NDT Plus. 2011;4(2):83-86. doi:10.1093/ndtplus/sfq211

49. Delanaye P, Cavalier E, Pottel H. Serum creatinine: not so simple! Nephron. 2017;136(4):302-308. doi:10.1159/000469669

50. Myers GL, Miller WG, Coresh J, et al. Recommendations for improving serum creatinine measurement: a report from the Laboratory Working Group of the National Kidney Disease Education Program. Clin Chem. 2006;52(1):5-18. doi:10.1373/ clinchem.2005.0525144

51. Coresh J, Hu JR, Bello AK, et al. Action plan for determining and monitoring the prevalence of chronic kidney disease. Kidney Int Suppl. 2017;7(2):63-70. doi:10.1016/j.kisu.2017.07.002

52. Delanaye P, Cavalier E, Cristol JP, Delanghe JR. Calibration and precision of serum creatinine and plasma cystatin $\mathrm{C}$ measurement: impact on the estimation of glomerular filtration rate. $J$ Nephrol. 2014;27(5):467-475. doi:10.1007/s40620-014-0087-7

53. Schmidt RL, Straseski JA, Raphael KL, et al. A Risk assessment of the jaffe vs enzymatic method for creatinine measurement in an outpatient population. PLoS One. 2015;10(11):e0143205. doi:10.1371/journal.pone.0143205 
54. Peake M, Whiting M. Measurement of serum creatinine--current status and future goals. Clin Biochem Rev. 2006;27(4):173-184.

55. Perazella MA, Coca SG, Kanbay M, Brewster UC, Parikh CR. Diagnostic value of urine microscopy for differential diagnosis of acute kidney injury in hospitalized patients. Clin J Am Soc Nephrol. 2008;3(6):1615-1619. doi:10.2215/CJN.02860608

56. Plewes K, Turner GDH, Dondorp AM. Pathophysiology, clinical presentation, and treatment of coma and acute kidney injury complicating falciparum malaria. Curr Opin Infect Dis. 2018;31 (1):69-77. doi:10.1097/QCO.0000000000000419

57. Maitland K, Levin M, English M, et al. Severe P. falciparum malaria in Kenyan children: evidence for hypovolaemia. QJM. 2003;96(6):427-434. doi:10.1093/qjmed/hcg077

58. Hörl WH. Nonsteroidal anti-inflammatory drugs and the kidney. Pharmaceuticals. 2010;3(7):2291-2321. doi:10.3390/ph3072291

59. Trzeciak S, Cinel I, Phillip Dellinger R, et al. Resuscitating the microcirculation in sepsis: the central role of nitric oxide, emerging concepts for novel therapies, and challenges for clinical trials. Acad Emerg Med. 2008;15(5):399-413. doi:10.1111/ j.1553-2712.2008.00109.x

60. Basile DP, Anderson MD, Sutton TA. Pathophysiology of acute kidney injury. Compr Physiol. 2012;2(2):1303-1353. doi:10.1002/cphy.c110041

61. Scholz H, Boivin FJ, Schmidt-Ott KM, et al. Kidney physiology and susceptibility to acute kidney injury: implications for renoprotection. Nat Rev Nephrol. 2021;17(5):335-349. doi:10.1038/s41581-021-00394-7

62. Olowu WA, Niang A, Osafo C, et al. Outcomes of acute kidney injury in children and adults in sub-Saharan Africa: a systematic review. Lancet Glob Health. 2016;4(4):e242-e250. doi:10.1016/ S2214-109X(15)00322-8

63. Nguansangiam S, Day NP, Hien TT, et al. A quantitative ultrastructural study of renal pathology in fatal Plasmodium falciparum malaria. Trop Med Int Health. 2007;12(9):1037-1050. doi:10.1111/j.1365-3156.2007.01881.x

64. Milner DA Jr, Whitten RO, Kamiza S, et al. The systemic pathology of cerebral malaria in African children. Front Cell Infect Microbiol. 2014;4:104. doi:10.3389/fcimb.2014.00104

65. Seydel KB, Milner DA Jr, Kamiza SB, Molyneux ME, Taylor TE. The distribution and intensity of parasite sequestration in comatose Malawian children. $J$ Infect Dis. 2006;194(2):208. doi:10.1086/505078

66. Kaur C, Pramanik A, Kumari K, et al. Renal detection of Plasmodium falciparum, Plasmodium vivax and Plasmodium knowlesi in malaria associated acute kidney injury: a retrospective case-control study. BMC Res Notes. 2020;13 (1):37. doi:10.1186/s13104-020-4900-1

67. Barber BE, Grigg MJ, Piera KA, et al. Intravascular haemolysis in severe Plasmodium knowlesi malaria: association with endothelial activation, microvascular dysfunction, and acute kidney injury. Emerg Microbes Infect. 2018;7(1):106. doi:10.1038/ s41426-018-0105-2

68. Plewes K, Kingston HWF, Ghose A, et al. Cell-free hemoglobin mediated oxidative stress is associated with acute kidney injury and renal replacement therapy in severe falciparum malaria: an observational study. BMC Infect Dis. 2017;17(1):313. doi:10.1186/s12879-017-2373-1

69. Plewes K, Royakkers AA, Hanson J, et al. Correlation of biomarkers for parasite burden and immune activation with acute kidney injury in severe falciparum malaria. Malar J. 2014;13:91. doi:10.1186/1475-2875-13-91

70. Elphinstone RE, Conroy AL, Hawkes M, et al. Alterations in systemic extracellular heme and hemopexin are associated with adverse clinical outcomes in ugandan children with severe malaria. $J$ Infect Dis. 2016;214(8):1268-1275. doi:10.1093/infdis/jiw357
71. Van Avondt K, Nur E, Zeerleder S. Mechanisms of haemolysis-induced kidney injury. Nat Rev Nephrol. 2019;15(11):671-692.

72. Jourde-Chiche N, Fakhouri F, Dou L, et al. Endothelium structure and function in kidney health and disease. Nat Rev Nephrol. 2019;15(2):87-108.

73. Verma SK, Molitoris BA. Renal endothelial injury and microvascular dysfunction in acute kidney injury. Semin Nephrol. 2015;35 (1):96-107. doi:10.1016/j.semnephrol.2015.01.010

74. Ouma BJ, Ssenkusu JM, Shabani E, et al. Endothelial activation, acute kidney injury, and cognitive impairment in pediatric severe malaria. Crit Care Med. 2020;48(9):e734-e743. doi:10.1097/ CCM.0000000000004469

75. Hanson J, Lee SJ, Hossain MA, et al. Microvascular obstruction and endothelial activation are independently associated with the clinical manifestations of severe falciparum malaria in adults: an observational study. BMC Med. 2015;13:122. doi:10.1186/s12916-015-0365-9

76. Turner GD, Morrison H, Jones M, et al. An immunohistochemical study of the pathology of fatal malaria. Evidence for widespread endothelial activation and a potential role for intercellular adhesion molecule-1 in cerebral sequestration. Am J Pathol. 1994;145 (5):1057-1069.

77. Avril M, Bernabeu M, Benjamin M, Brazier AJ, Smith JD, Miller LH. Interaction between endothelial protein $\mathrm{C}$ receptor and intercellular adhesion molecule 1 to mediate binding of Plasmodium falciparum-infected erythrocytes to endothelial cells. mBio. 2016;7(4). doi:10.1128/mBio.00615-16

78. Tuikue Ndam N, Moussiliou A, Lavstsen T, et al. Parasites causing cerebral falciparum malaria bind multiple endothelial receptors and express EPCR and ICAM-1-binding PfEMP1. J Infect Dis. 2017;215(12):1918-1925. doi:10.1093/infdis/jix230

79. Yeo TW, Lampah DA, Gitawati R, et al. Impaired nitric oxide bioavailability and L-arginine reversible endothelial dysfunction in adults with falciparum malaria. J Exp Med. 2007;204 (11):2693-2704. doi:10.1084/jem.20070819

80. Turner L, Lavstsen T, Berger SS, et al. Severe malaria is associated with parasite binding to endothelial protein $\mathrm{C}$ receptor. Nature. 2013;498(7455):502-505. doi:10.1038/nature12216

81. Turner GD, Ly VC, Nguyen TH, et al. Systemic endothelial activation occurs in both mild and severe malaria. Correlating dermal microvascular endothelial cell phenotype and soluble cell adhesion molecules with disease severity. Am J Pathol. 1998;152(6):1477-1487.

82. Hawkes M, Elphinstone RE, Conroy AL, Kain KC. Contrasting pediatric and adult cerebral malaria: the role of the endothelial barrier. Virulence. 2013;4(6):543-555. doi:10.4161/viru.25949

83. Conroy AL, Phiri H, Hawkes M, et al. Endothelium-based biomarkers are associated with cerebral malaria in Malawian children: a retrospective case-control study. PLoS One. 2010;5(12): e15291. doi:10.1371/journal.pone.0015291

84. Beare NA, Harding SP, Taylor TE, Lewallen S, Molyneux ME. Perfusion abnormalities in children with cerebral malaria and malarial retinopathy. $J$ Infect Dis. 2009;199(2):263-271. doi: $10.1086 / 595735$

85. Bernabeu M, Smith JD. EPCR and malaria severity: the center of a perfect storm. Trends Parasitol. 2017;33(4):295-308. doi:10.1016/j.pt.2016.11.004

86. Jespersen JS, Wang CW, Mkumbaye SI, et al. Plasmodium falciparum var genes expressed in children with severe malaria encode CIDR 1 domains. EMBO Mol Med. 2016;8(8):839-850. doi:10.15252/emmm.201606188

87. Kessler A, Dankwa S, Bernabeu M, et al. Linking EPCR-binding PfEMP1 to brain swelling in pediatric cerebral malaria. Cell Host Microbe. 2017;22(5):601-614 e605. doi:10.1016/j.chom.2017.09.009

88. Petersen JE, Mkumbaye SI, Vaaben AV, et al. Plasma Ang2 and ADAM17 levels are elevated during clinical malaria; Ang2 level correlates with severity and expression of EPCR-binding PfEMP1. Sci Rep. 2016;6:35950. doi:10.1038/srep35950 
89. Shabani E, Hanisch B, Opoka RO, Lavstsen T, John CC. Plasmodium falciparum EPCR-binding PfEMP1 expression increases with malaria disease severity and is elevated in retinopathy negative cerebral malaria. BMC Med. 2017;15:183. doi:10.1186/s12916-017-0945-y

90. Lattenist L, Kers J, Claessen N, et al. Renal and urinary levels of endothelial protein $\mathrm{C}$ receptor correlate with acute renal allograft rejection. PLoS One. 2013;8(5):e64994. doi:10.1371/journal. pone. 0064994

91. Müller GA, Markovic-Lipkovski J, Müller CA. Intercellular adhesion molecule-1 expression in human kidneys with glomerulonephritis. Clin Nephrol. 1991;36(4):203-208.

92. David PH, Handunnetti SM, Leech JH, Gamage P, Mendis KN. Rosetting: a new cytoadherence property of malaria-infected erythrocytes. Am J Trop Med Hyg. 1988;38(2):289-297. doi:10.4269/ajtmh.1988.38.289

93. Rowe A, Obeiro J, Newbold CI, Marsh K. Plasmodium falciparum rosetting is associated with malaria severity in Kenya. Infect Immun. 1995;63(6):2323-2326. doi:10.1128/ IAI.63.6.2323-2326.1995

94. Rivera-Correa J, Conroy AL, Opoka RO, et al. Autoantibody levels are associated with acute kidney injury, anemia and post-discharge morbidity and mortality in Ugandan children with severe malaria. Sci Rep. 2019;9(1):14940. doi:10.1038/ s41598-019-51426-z

95. Murugan R, Karajala-Subramanyam V, Lee M, et al. Acute kidney injury in non-severe pneumonia is associated with an increased immune response and lower survival. Kidney Int. 2010;77(6):527-535. doi:10.1038/ki.2009.502

96. Herter JM, Rossaint J, Spieker T, Zarbock A. Adhesion molecules involved in neutrophil recruitment during sepsis-induced acute kidney injury. J Innate Immun. 2014;6(5):597-606. doi:10.1159/ 000358238

97. Lerolle N, Nochy D, Guérot E, et al. Histopathology of septic shock induced acute kidney injury: apoptosis and leukocytic infiltration. Intensive Care Med. 2010;36(3):471-478. doi:10.1007/s00134-009-1723-x

98. Rabb H, Griffin MD, McKay DB, et al. Inflammation in AKI: current understanding, key questions, and knowledge gaps. J Am Soc Nephrol. 2016;27(2):371-379. doi:10.1681/ASN.2015030261

99. Goldstein SL, Chawla L, Ronco C, Kellum JA. Renal recovery. Crit Care. 2014;18(1):301. doi:10.1186/cc13180

100. Cerda J, Mohan S, Garcia-Garcia G, et al. Acute kidney injury recognition in low- and middle-income countries. Kidney Int Rep. 2017;2(4):530-543. doi:10.1016/j.ekir.2017.04.009

101. Radyowijati A, Haak H. Improving antibiotic use in low-income countries: an overview of evidence on determinants. Soc Sci Med. 2003;57(4):733-744. doi:10.1016/S0277-9536(02)00422-7

102. Plewes K, Kingston HWF, Ghose A, et al. Acetaminophen as a renoprotective adjunctive treatment in patients with severe and moderately severe falciparum malaria: a randomized, controlled, open-label trial. Clin Infect Dis. 2018;67(7):991-999. doi:10.1093/cid/ciy213

103. Van Driest SL, Jooste EH, Shi Y, et al. Association between early postoperative acetaminophen exposure and acute kidney injury in pediatric patients undergoing cardiac surgery. JAMA Pediatr. 2018;172(7):655-663. doi:10.1001/jamapediatrics.2018.0614

104. Desgrouas M, Boulain T. Paracetamol use and lowered risk of acute kidney injury in patients with rhabdomyolysis. $J$ Nephrol. 2021. doi:10.1007/s40620-020-00950-7

105. Maitland K, Kiguli S, Opoka RO, et al. Mortality after fluid bolus in African children with severe infection. N Engl J Med. 2011;364 (26):2483-2495. doi:10.1056/NEJMoa1101549
106. Hanson JP, Lam SW, Mohanty S, et al. Fluid resuscitation of adults with severe falciparum malaria: effects on acid-base status, renal function, and extravascular lung water. Crit Care Med. 2013;41(4):972-981. doi:10.1097/CCM.0b013e31827466d2

107. Ishioka H, Plewes K, Pattnaik R, et al. Associations between restrictive fluid management and renal function and tissue perfusion in adults with severe falciparum malaria: a Prospective Observational Study. J Infect Dis. 2020;221(2):285-292. doi:10.1093/infdis/jiz449

108. World Health Organization. Management of Severe Malaria: A Practical Handbook. 3rd ed. 2013.

109. Waller D, Krishna S, Crawley J, et al. Clinical features and outcome of severe malaria in Gambian children. Clin Infect Dis. 1995;21(3):577-587. doi:10.1093/clinids/21.3.577

110. Dondorp AM, Fanello CI, Hendriksen IC, et al. Artesunate versus quinine in the treatment of severe falciparum malaria in African children (AQUAMAT): an open-label, randomised trial. Lancet. 2010;376(9753):1647-1657. doi:10.1016/S0140-6736(10)61924-1

111. Conroy AL, Hawkes M, Hayford K, et al. Prospective validation of pediatric disease severity scores to predict mortality in Ugandan children presenting with malaria and non-malaria febrile illness. Crit Care. 2015;19:47. doi:10.1186/s13054-0150773-4

112. Baelani I, Jochberger S, Laimer T, et al. Availability of critical care resources to treat patients with severe sepsis or septic shock in Africa: a self-reported, continent-wide survey of anaesthesia providers. Crit Care. 2011;15(1):R10. doi:10.1186/cc9410

113. Madrid L, Sitoe A, Varo R, et al. Continuous determination of blood glucose in children admitted with malaria in a rural hospital in Mozambique. Malar J. 2017;16(1):184. doi:10.1186/s12936017-1840-X

114. Hawkes MT, Conroy AL, Opoka RO, et al. Inhaled nitric oxide as adjunctive therapy for severe malaria: a randomized controlled trial. Malar J. 2015;14(1):421. doi:10.1186/s12936-015-0946-2

115. Nkoy AB, Ndiyo YM, Matoka TT, et al. A promising pediatric peritoneal dialysis experience in a resource-limited setting with the support of saving young lives program. Perit Dial Int. 2020;40(5):504-508. doi:10.1177/0896860819887286

116. Palmer D, Lawton WJ, Barrier C Jr, et al. Peritoneal dialysis for AKI in cameroon: commercial vs locally-made solutions. Perit Dial Int. 2018;38(4):246-250. doi:10.3747/pdi.2017.00190

117. Barrantes F, Tian J, Vazquez R, Amoateng-Adjepong Y, Manthous CA. Acute kidney injury criteria predict outcomes of critically ill patients. Crit Care Med. 2008;36(5):1397-1403. doi:10.1097/CCM.0b013e318168fbe0

118. Alkandari O, Eddington KA, Hyder A, et al. Acute kidney injury is an independent risk factor for pediatric intensive care unit mortality, longer length of stay and prolonged mechanical ventilation in critically ill children: a two-center retrospective cohort study. Crit Care. 2011;15(3):R146. doi:10.1186/cc10269

119. Schneider J, Khemani R, Grushkin C, Bart R. Serum creatinine as stratified in the RIFLE score for acute kidney injury is associated with mortality and length of stay for children in the pediatric intensive care unit. Crit Care Med. 2010;38(3):933-939. doi:10.1097/CCM.0b013e3181cd12e1

120. Kapoor K, Gupta S. Malarial acute kidney injury in a paediatric intensive care unit. Trop Doct. 2012;42(4):203-205. doi:10.1258/ td.2012.120196

121. Horkan CM, Purtle SW, Mendu ML, Moromizato T, Gibbons FK, Christopher KB. The association of acute kidney injury in the critically ill and postdischarge outcomes: a cohort study*. Crit Care Med. 2015;43(2):354-364. doi:10.1097/CCM.000 0000000000706 
122. Sawhney S, Marks A, Fluck N, McLernon DJ, Prescott GJ, Black C. Acute kidney injury as an independent risk factor for unplanned 90-day hospital readmissions. BMC Nephrol. 2017;18 (1):9. doi:10.1186/s12882-016-0430-4

123. Koulouridis I, Price LL, Madias NE, Jaber BL. Hospital-acquired acute kidney injury and hospital readmission: a cohort study. $\mathrm{Am}$ J Kidney Dis. 2015;65(2):275-282. doi:10.1053/j. ajkd.2014.08.024

124. Brown JR, Hisey WM, Marshall EJ, et al. Acute kidney injury severity and long-term readmission and mortality after cardiac surgery. Ann Thorac Surg. 2016;102(5):1482-1489. doi:10.1016/ j.athoracsur.2016.04.020

125. Wahl TS, Graham LA, Morris MS, et al. Association between preoperative proteinuria and postoperative acute kidney injury and readmission. JAMA Surg. 2018;153(9):e182009. doi:10.1001/jamasurg.2018.2009

126. Hessey E, Morissette G, Lacroix J, et al. Healthcare utilization after acute kidney injury in the pediatric intensive care unit. Clin $J$ Am Soc Nephrol. 2018;13(5):685-692. doi:10.2215/ CJN.09350817

127. Calis JC, Phiri KS, Faragher EB, et al. Severe anemia in Malawian children. $N$ Engl J Med. 2008;358(9):888-899. doi:10.1056/NEJMoa072727

128. Phiri KS, Calis JC, Faragher B, et al. Long term outcome of severe anaemia in Malawian children. PLoS One. 2008;3(8): e2903. doi:10.1371/journal.pone.0002903

129. Opoka RO, Hamre KES, Brand N, Bangirana P, Idro R, John CC. High postdischarge morbidity in ugandan children with severe malarial anemia or cerebral malaria. J Pediatric Infect Dis Soc. 2017;6(3):e41-e48. doi:10.1093/jpids/piw060

130. Kwambai TK, Dhabangi A, Idro R, et al. Malaria chemoprevention in the postdischarge management of severe anemia. $N$ Engl $J$ Med. 2020;383(23):2242-2254. doi:10.1056/NEJMoa2002820

131. Opoka RO, Waiswa A, Harriet N, John CC, Tumwine JK, Karamagi C. Blackwater fever in Ugandan children with severe anemia is associated with poor postdischarge outcomes: a Prospective Cohort Study. Clin Infect Dis. 2020;70 (11):2247-2254. doi:10.1093/cid/ciz648

132. Bodi JM, Nsibu CN, Aloni MN, et al. Black water fever associated with acute renal failure among congolese children in Kinshasa. Saudi J Kidney Dis Transpl. 2014;25(6):1352-1358. doi:10.4103/1319-2442.144326

133. Olupot-Olupot P, Engoru C, Uyoga S, et al. High frequency of blackwater fever among children presenting to hospital with severe febrile illnesses in Eastern Uganda. Clin Infect Dis. 2017;64(7):939-946. doi:10.1093/cid/cix003

134. Hickson MR, Conroy AL, Bangirana P, et al. Acute kidney injury in Ugandan children with severe malaria is associated with long-term behavioral problems. PLoS One. 2019;14(12): e0226405. doi:10.1371/journal.pone.0226405

135. Datta D, Conroy AL, Castelluccio PF, et al. Elevated cerebrospinal fluid tau protein concentrations on admission are associated with long-term neurologic and cognitive impairment in Ugandan children with cerebral malaria. Clin Infect Dis. 2020;70 (6):1161-1168. doi:10.1093/cid/ciz325

136. Fitzgerald JC, Basu RK, Akcan-Arikan A, et al. Acute kidney injury in pediatric severe sepsis: an independent risk factor for death and new disability. Crit Care Med. 2016;44(12):2241-2250. doi:10.1097/CCM.0000000000002007

137. Starr MC, Banks R, Reeder RW, et al. Severe acute kidney injury is associated with increased risk of death and new morbidity after pediatric septic shock. Pediatr Crit Care Med. 2020;21(9):e686e695. doi:10.1097/PCC.0000000000002418
138. Chawla LS, Bellomo R, Bihorac A, et al. Acute kidney disease and renal recovery: consensus report of the Acute Disease Quality Initiative (ADQI) 16 workgroup. Nat Rev Nephrol. 2017;13 (4):241-257. doi:10.1038/nrneph.2017.2

139. Chawla LS, Eggers PW, Star RA, Kimmel PL. Acute kidney injury and chronic kidney disease as interconnected syndromes. N Engl J Med. 2014;371(1):58-66. doi:10.1056/NEJMra1214243

140. Leung KC, Tonelli M, James MT. Chronic kidney disease following acute kidney injury-risk and outcomes. Nat Rev Nephrol. 2013;9(2):77-85. doi:10.1038/nrneph.2012.280

141. Goldstein SL. Renal recovery at different ages. Nephron Clin Pract. 2014;127(1-4):21-24. doi:10.1159/000363679

142. Basile DP, Bonventre JV, Mehta R, et al. Progression after AKI: understanding maladaptive repair processes to predict and identify therapeutic treatments. J Am Soc Nephrol. 2016;27 (3):687-697. doi:10.1681/ASN.2015030309

143. Sigurjonsdottir VK, Chaturvedi S, Mammen C, Sutherland SM. Pediatric acute kidney injury and the subsequent risk for chronic kidney disease: is there cause for alarm? Pediatr Nephrol. 2018;33(11):2047-2055. doi:10.1007/s00467-017-3870-6

144. Cooper DS, Claes D, Goldstein SL, et al. Follow-up Renal Assessment of Injury Long-term after Acute Kidney Injury (FRAIL-AKI). Clin J Am Soc Nephrol. 2016;11(1):21-29. doi: $10.2215 /$ CJN.04240415

145. Greenberg JH, Zappitelli M, Devarajan P, et al. Kidney outcomes 5 years after pediatric cardiac surgery: the TRIBE-AKI Study. JAMA Pediatr. 2016;170(11):1071-1078. doi:10.1001/ jamapediatrics.2016.1532

146. Madsen NL, Goldstein SL, Frøslev T, Christiansen CF, Olsen M. Cardiac surgery in patients with congenital heart disease is associated with acute kidney injury and the risk of chronic kidney disease. Kidney Int. 2017;92(3):751-756. doi:10.1016/j. kint.2017.02.021

147. Hollander SA, Montez-Rath ME, Axelrod DM, et al. Recovery from acute kidney injury and $\mathrm{CKD}$ following heart transplantation in children, adolescents, and young adults: a Retrospective Cohort Study. Am J Kidney Dis. 2016;68(2):212-218. doi:10.1053/j.ajkd.2016.01.024

148. Menon S, Kirkendall ES, Nguyen H, Goldstein SL. Acute kidney injury associated with high nephrotoxic medication exposure leads to chronic kidney disease after 6 months. J Pediatr. 2014;165(3):522-527 e522. doi:10.1016/j.jpeds.2014.04.058

149. Mammen C, Al Abbas A, Skippen P, et al. Long-term risk of $\mathrm{CKD}$ in children surviving episodes of acute kidney injury in the intensive care unit: a prospective cohort study. Am J Kidney Dis. 2012;59(4):523-530. doi:10.1053/j.ajkd.2011.10.048

150. Raimann JG, Riella MC, Levin NW. International society of nephrology's 0by25 initiative (zero preventable deaths from acute kidney injury by 2025): focus on diagnosis of acute kidney injury in low-income countries. Clin Kidney J. 2018;11(1):12-19. doi:10.1093/ckj/sfw134

151. Calice-Silva V, Vieira MA, Raimann JG, et al. Saliva urea nitrogen dipstick - a novel bedside diagnostic tool for acute kidney injury. Clin Nephrol. 2014;82(12):358-366. doi:10.5414/ CN108370

152. Evans R, Calice-Silva V, Raimann JG, et al. Diagnostic performance of a saliva urea nitrogen dipstick to detect kidney disease in Malawi. Kidney Int Rep. 2017;2(2):219-227. doi:10.1016/j. ekir.2016.12.006

153. Raimann JG, Calice-Silva V, Thijssen S, et al. Saliva urea nitrogen continuously reflects blood urea nitrogen after acute kidney injury diagnosis and management: longitudinal observational data from a Collaborative, International, Prospective, Multicenter Study. Blood Purif. 2016;42(1):64-72. doi:10.1159/000445041 
154. Calice-Silva V, Sacomboio E, Raimann JG, et al. Diagnostic performance of salivary urea nitrogen dipstick to detect and monitor acute kidney disease in patients with malaria. Malar $J$. 2018;17(1):477. doi:10.1186/s12936-018-2627-4

155. Evans RDR, Hemmila U, Mzinganjira H, et al. Diagnostic performance of a point-of-care saliva urea nitrogen dipstick to screen for kidney disease in low-resource settings where serum creatinine is unavailable. BMJ Global Health. 2020;5:5. doi:10.1136/ bmjgh-2020-002312

156. Hussein RH, Calice-Silva V, Evans R, et al. Diagnosis of acute kidney injury in children hospitalized in a Sub-Saharan African Unit by saliva urea nitrogen dipstick test. Blood Purif. 2020;49(12):185-196. doi:10.1159/000504080

157. Ning M, Mao X, Niu Y, Tang B, Shen H. Usefulness and limitations of neutrophil gelatinase-associated lipocalin in the assessment of kidney diseases. $J$ Lab Precis Med. 2018;3(1):1. doi:10.21037/jlpm.2017.12.09

158. Bjornstad EC, Muronya W, Kamija M, et al. Validity of urine NGALds dipstick for acute kidney injury in a Malawian trauma cohort. Kidney Int Rep. 2020;5(10):1791-1798. doi:10.1016/j. ekir.2020.07.019

159. Ataei N, Bazargani B, Ameli S, et al. Early detection of acute kidney injury by serum cystatin $\mathrm{C}$ in critically ill children. Pediatr Nephrol. 2014;29(1):133-138. doi:10.1007/s00467-013-2586-5

160. Dharnidharka VR, Kwon C, Stevens G. Serum cystatin C is superior to serum creatinine as a marker of kidney function: a meta-analysis. Am J Kidney Dis. 2002;40(2):221-226. doi:10.1053/ajkd.2002.34487
161. Devarajan P. Neutrophil gelatinase-associated lipocalin: a promising biomarker for human acute kidney injury. Biomark Med. 2010;4(2):265-280. doi:10.2217/bmm.10.12

162. Schley G, Koberle C, Manuilova E, et al. Comparison of plasma and urine biomarker performance in acute kidney injury. PLoS One. 2015;10(12):e0145042. doi:10.1371/journal. pone. 0145042

163. Westhoff JH, Tonshoff B, Waldherr S, et al. Urinary Tissue Inhibitor of Metalloproteinase-2 (TIMP-2) * Insulin-Like Growth Factor-Binding Protein 7 (IGFBP7) predicts adverse outcome in pediatric acute kidney injury. PLoS One. 2015;10(11): e0143628. doi:10.1371/journal.pone.0143628

164. Araujo CB, de Oliveira Neves FM, de Freitas DF, et al. Angiopoietin-2 as a predictor of acute kidney injury in critically ill patients and association with ARDS. Respirology. 2019;24 (4):345-351. doi:10.1111/resp.13464

165. $\mathrm{Xu} \mathrm{K}$, Rosenstiel $\mathrm{P}$, Paragas $\mathrm{N}$, et al. Unique transcriptional programs identify subtypes of AKI. J Am Soc Nephrol. 2017;28 (6):1729-1740. doi:10.1681/ASN.2016090974

166. Dai X, Zeng Z, Fu C, Zhang S, Cai Y, Chen Z. Diagnostic value of neutrophil gelatinase-associated lipocalin, cystatin $\mathrm{C}$, and soluble triggering receptor expressed on myeloid cells- 1 in critically ill patients with sepsis-associated acute kidney injury. Crit Care. 2015;19(1):223. doi:10.1186/s13054-015-0941-6

\section{Publish your work in this journal}

The International Journal of Nephrology and Renovascular Disease is an international, peer-reviewed open-access journal focusing on the pathophysiology of the kidney and vascular supply. Epidemiology, screening, diagnosis, and treatment interventions are covered as well as basic

Submit your manuscript here: https://www.dovepress.com/international-journal-of-nephrology-and-renovascular-disease-journal science, biochemical and immunological studies. The manuscript management system is completely online and includes a very quick and fair peer-review system, which is all easy to use. Visit http://www.dovepress.com/testimonials.php to read real quotes from published authors. 